2010

\title{
Modeling the Vertical Distributions of Downwelling Plane Irradiance and Diffuse Attenuation Coefficient in Optically Deep Waters
}

X.J.Pan

Richard C.Zimmerman

Old Dominion University, rzimmerm@odu.edu

Follow this and additional works at: https://digitalcommons.odu.edu/oeas_fac_pubs

Part of the Marine Biology Commons, and the Oceanography Commons

\section{Repository Citation}

Pan, X. J. and Zimmerman, Richard C., "Modeling the Vertical Distributions of Downwelling Plane Irradiance and Diffuse Attenuation Coefficient in Optically Deep Waters" (2010). OEAS Faculty Publications. 117.

https://digitalcommons.odu.edu/oeas_fac_pubs/117

\section{Original Publication Citation}

Pan, X.J., \& Zimmerman, R.C. (2010). Modeling the vertical distributions of downwelling plane irradiance and diffuse attenuation coefficient in optically deep waters. Journal of Geophysical Research-Oceans, 115, 14. doi: 10.1029/2009jc006039 


\title{
Modeling the vertical distributions of downwelling plane irradiance and diffuse attenuation coefficient in optically deep waters
}

\begin{abstract}
Xiaoju Pan ${ }^{1,2}$ and Richard C. Zimmerman ${ }^{1}$
Received 8 December 2009; revised 25 March 2010; accepted 6 April 2010; published 17 August 2010.

[1] The diffuse attenuation coefficient $\left(K_{d}\right)$ is critical to understand the vertical distribution of underwater downwelling irradiance $\left(E_{d}\right)$. Theoretically $E_{d}$ is composed of the direct solar beam and the diffuse sky irradiance. Applying the statistical results from Hydrolight radiative transfer simulations, $K_{d}$ is expressed into a mathematical equation (named as PZ06) integrated from the contribution of direct solar beam and diffuse sky irradiance with the knowledge of sky and water conditions. The percent root mean square errors (RMSE) for the vertical distribution of $E_{d}(z)$ under various sky and water conditions between PZ06 and Hydrolight results are typically less than 4\%. Field observations from the southern Middle Atlantic Bight (SMAB) and global in situ data set (NOMAD) also confirmed the validity of PZ06 in reproducing $K_{d}$. PZ06 provides an alternative and improvement to the simpler models (e.g., Gordon, 1989; and Kirk, 1991) and an operational ocean color algorithm, while the latter two kinds of models are valid to limited sky and water conditions. PZ06 can be applied to study $K_{d}$ from satellite remotely sensed images and seems to improve $K_{d}$ derivation over current operational ocean color algorithm.
\end{abstract}

Citation: Pan, X., and R. C. Zimmerman (2010), Modeling the vertical distributions of downwelling plane irradiance and diffuse attenuation coefficient in optically deep waters, J. Geophys. Res., 115, C08016, doi:10.1029/2009JC006039.

\section{Introduction}

[2] According to the Lambert-Beer Law, underwater downwelling plane irradiance $\left[E_{d}(z)\right]$ decreases exponentially with depth $(z)$ :

$$
E_{d}(z)=E_{d}\left(0^{-}\right) \exp \left[-\bar{K}_{d}(z) \times z\right] .
$$

Equation (1) is wavelength dependent. For simplification, the wavelength dependence is not shown for all equations in this paper unless noted. $\bar{K}_{d}(z)$ is defined as the average value of the diffuse attenuation coefficient $\left[K_{d}(z)\right]$ from the surface down to depth $z$, and represents an aggregate expression of the impact of the inherent optical properties (IOPs) on radiance distribution. As such, it is often highly correlated with the concentration of optically active materials, including phytoplankton, suspended sediments, and colored dissolved organic matter (CDOM) [Gordon, 1989; Kirk, 1991, 1994; Mobley, 1994]. $\bar{K}_{d}$ can be derived remotely from empirical algorithms based on the blue-to-green ratio of normalized water-leaving radiance $\left(n L_{w}\right)$ or remote sensing reflectance $\left(R_{r s}\right)$ [Mueller, 2000; Signorini et al.,

\footnotetext{
${ }^{1}$ Department of Ocean, Earth, and Atmospheric Sciences, Old Dominion University, Norfolk, Virginia, USA.

${ }^{2}$ Now at Research Center for Environmental Changes, Academia Sinica, Taipei, Taiwan.

Copyright 2010 by the American Geophysical Union. 0148-0227/10/2009JC006039
}

2003], and from quasi-analytical algorithms based on the relationships to IOPs measured in situ or simulated [Gordon, 1989; Kirk, 1991, 1994; Mobley, 1994; Lee et al., 2005; Wang et al., 2009]. The empirical algorithms do not require detailed knowledge of bio-optics, but they suffer from large uncertainty and are insufficient for understanding temporal or spatial variations in $K_{d}(z)$. Quasi-analytical expressions based on water column optical properties often improve generality of the empirical algorithms, but the development of a simple and accurate derivation of $K_{d}(z)$ from IOPs remains elusive [Gordon, 1989; Kirk, 1994; Mobley, 1994; Wang et al., 2009]. Although radiative transfer models (RTMs), such as Monte Carlo simulations and Hydrolight (copyright 1998-2001, C. Mobley, Sequoia Scientific), provide "exact" solutions to predict $K_{d}(z)$ from IOPs, they are seldom applied to satellite remote sensing since they are too complicated (time expensive by using depth-by-depth simulations) to survey rapidly and routinely for large areas. Moreover, RTMs cannot be inverted to determine IOPs from the apparent optical properties (AOPs) of remote sensing reflectance $\left(R_{r s}\right)$ and $K_{d}$, which limits the further application of RTMs in biogeochemical studies.

[3] $K_{d}(z)$ is a relatively simple quantity to measure in situ, but its relationship to coefficients of absorption $(a)$, scattering $(b)$, and backscattering $\left(b_{b}\right)$ is much more complicated because $K_{d}(z)$ is an apparent optical property (AOP) influenced by the angular structure of the submarine light field in addition to the inherent optical characteristics of the medium 
[Kirk, 1994; Mobley, 1994]. The simplest form (named as G89), provided by Gordon [1989] and valid only for limited sky and oceanic conditions (e.g., medium solar zenith angle and absorption-dominant water), is often presented as:

$$
K_{d}=1.0395 \frac{a+b_{b}}{\bar{\mu}_{w}}
$$

Here $\bar{\mu}_{w}$ is defined as the average cosine of the incident angle of direct solar beam just below the surface $\left(\theta_{w}\right)$ after accounting for refraction from the solar zenith angle $\left(\theta_{s}\right)$ by Snell's Law [Kirk, 1994; Mobley, 1994]:

$$
\sin \left(\theta_{w}\right)=\frac{\sin \left(\theta_{s}\right)}{1.34}
$$

To make the equations simply, we assumed the vertical distributions of IOPs are vertically homogeneous or can be represented by their mean values from the surface to certain depth. Gordon [1989] model does not account for the fact that scattering typically causes $K_{d}$ to increase asymptotically with depth in most natural waters [Mobley, 1994], which often causes it to overestimate $E_{d}(z)$.

[4] Kirk [1991, 1994] derived a slightly more complicated relationship from a series of Monte Carlo simulations:

$$
K_{d}=\frac{\left(a^{2}+G a b\right)^{1 / 2}}{\bar{\mu}_{w}}
$$

Here $G$ is a coefficient related to $\bar{\mu}_{w}$ and the shape of scattering phase function. Unfortunately, constraining the latter is so complicated as to make $G$ extremely difficult to parameterize, especially when the sun is not directly overhead. Kirk [1991] approximated that $G=0.425 \bar{\mu}_{w}-0.19$ and $G=0.473 \bar{\mu}_{w}-0.218$ in calculating the average $K_{d}$ from the surface down to the depth receiving $1 \%$ and $10 \%$ of surface irradiance, respectively. Such approximations, however, are not always appropriate for all water conditions, especially for turbid coastal waters such as the Chesapeake Bay estuary.

[5] More recently, Mobley [1994] summarized a two-flow model and presented a tantalizingly simple relationship between $K_{d}(z)$ and the IOPs:

$$
K_{d}(z)=\frac{a+b_{b}}{\bar{\mu}_{d}(z)}-R(z) \frac{b_{b}}{\overline{\mu_{u}}(z)}
$$

Here $\bar{\mu}_{d}$ and $\bar{\mu}_{u}$ represent the average cosines of downward and upward plane irradiances, respectively, and $R$ is the ratio of upwelling plane irradiance $\left(E_{u}\right)$ to downwelling plane irradiance $\left(E_{d}\right)$. Lee et al. [2005] developed a quasi-analytical approach to $K_{d}(z)$ based on equation (5) and the results of radiative transfer modeling, and rewrote it as:

$$
\overline{K_{d}}(z)=m_{0}(z) a+v(z) b_{b}
$$

The parameterization of $m_{0}(z)$ and $v(z)$, however, requires the use of a lookup table (LUT) [Lee et al., 2005; Liu et al., 2002; Morel and Gentili, 1993], which may not be appropriate for all water masses. Since $R$ is typically small in optically deep water, the second term in the right side of equation (5) is often ignored, leading to the common expression:

$$
K_{d}(z) \approx \frac{a+b_{b}}{\bar{\mu}_{d}(z)}
$$

Hydrolight simulations show that the difference between $K_{d}$ calculated from equations (5) and (7) is typically less than $1 \%$ for deep waters. This simple relationship of equation (7) offers a potential solution to relate the vertical variation of $K_{d}$ and $E_{d}$ to the IOPs, but the vertical distribution of $\bar{\mu}_{d}$ and the method to estimate it are not well established. Estimating $\bar{\mu}_{d}$ is more difficult than $\bar{\mu}_{w}$ because it includes the angular distribution of sky radiance as diffracted by airborne molecules and aerosols and water-borne molecules and particles, in addition to the direct solar beam. It is also explicitly variable with depth $(z)$.

[6] An asymptotic closure theory has been developed that describes the angular distribution of plane irradiance as a function of depth (z) [Bannister, 1992; Berwald et al., 1995; Zaneveld, 1989]. On the basis of this theory, the vertical distribution of $K_{d}$ at relatively high solar position (e.g., $\theta_{s}=0^{\circ}$ ) can be expressed as:

$$
\begin{aligned}
K_{d}\left(\theta_{s}=0^{\circ}, z\right)= & K_{d}(\infty) \\
& +\left[K_{d}\left(\theta_{s}=0^{\circ}, 0\right)-K_{d}(\infty)\right] \exp (-P c z)
\end{aligned}
$$

The exponential slope $(P)$ represents the vertical decay rate of $K_{d}\left(\theta_{s}=0^{\circ}, z\right)$ toward its asymptotic value in infinitely deep water $\left[K_{d}(\infty)\right]$ along with the beam optical depth $(\xi=$ $c z$, where $c$ represents beam attenuation coefficient). However, Hydrolight simulations show that this asymptotic closure model becomes invalid when solar elevation is low (e.g., $\theta_{s}>40^{\circ}$ ). A more complicated model, such as a fiveparameter asymptotic closure model expressed as the sum of two exponential functions [McCormick, 1995], can describe $K_{d}(z)$ more accurately, but explaining the derived parameters and estimating them from the IOPs and $\theta_{s}$ remain extremely difficult.

[7] In this paper, we developed a sufficiently accurate and robust quasi-analytical approach (named as PZ06) based on the analysis of Hydrolight simulations to estimate $K_{d}(z)$ from measurable or derivable IOPs. This approach provides a bridge to biogeochemical studies by inverse modeling of IOPs and estimation of light availability reaching to the floor. The calculations were verified against Hydrolight simulations and validated against in situ observations. PZ06 was also compared to the much simpler G89 model (equation (2)), the Kirk [1991] model (equation (4) by using the coefficients in calculating the average $K_{d}$ from the surface to the depth receiving $1 \%$ of surface irradiance; named as K91), and the operationally empirical algorithm (named as S09; equation (9)) [Mueller, 2000; Signorini et al., 2003] with the newly derived empirical coefficients in the Ocean Color Reprocessing 2009 (http://oceancolor.gsfc.nasa.gov/ REPROCESSING/R2009/kdv4/).

$$
K_{490} S 09=0.0166+10^{a_{0}+a_{1} X+a_{2} X^{2}+a_{3} X^{3}+a_{4} X^{4}}
$$

Here, $\mathrm{X}$ represents the ratio of remote sensing reflectance $\left(R_{r S}\right), X=\log \left[R_{r S}\left(\lambda_{1}\right) / R_{r S}\left(\lambda_{2}\right)\right]$, and $\lambda_{1}$ and $\lambda_{2}$ are 490 and $555 \mathrm{~nm}$ for the Sea-viewing Wide Field-of-view Sensor (SeaWiFS). The derived coefficients $\mathrm{a}_{0}, \mathrm{a}_{1}, \mathrm{a}_{2}, \mathrm{a}_{3}$, and $\mathrm{a}_{4}$ are $-0.8515,-1.8263,1.8714,-2.4414$, and -1.0690 , respectively. Finally, we applied PZ06 to estimate the distributions 


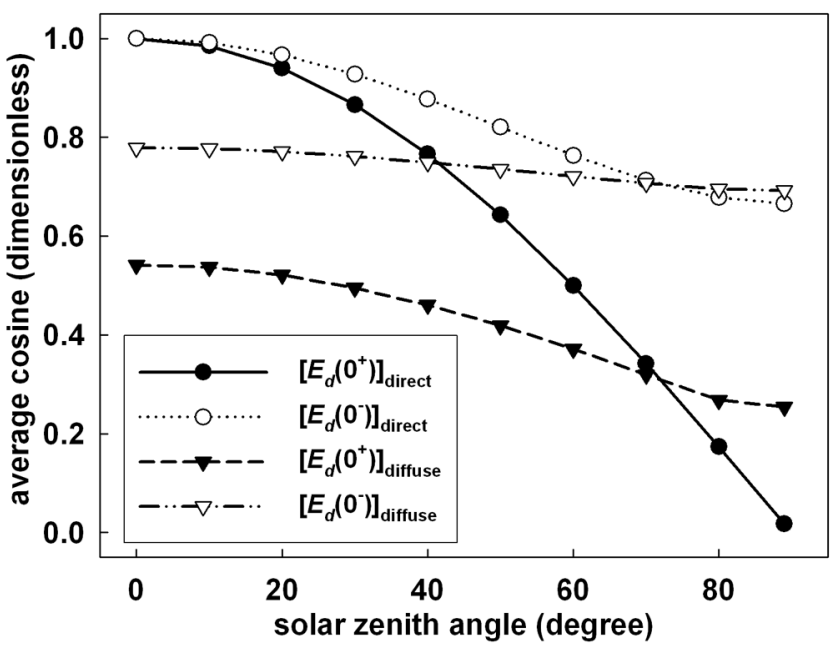

Figure 1. Dependence of the average cosines of downwelling irradiance on the solar zenith angle. $\mathrm{E}_{\mathrm{d}}\left(0^{+}\right)$and $\mathrm{E}_{\mathrm{d}}\left(0^{-}\right)$indicate downwelling irradiance above and below the surface, respectively. Calculations were based on Hydrolight simulations for clear sky.

of diffuse attenuation coefficient in the southern Middle Atlantic Bight (SMAB) from satellite imagery.

\section{Theory Behind PZ06}

[8] The incident $E_{d}$ entering the water column is assumed to obey a constant transmission factor across the air-sea interface $\left[0.98 \mathrm{E}_{\mathrm{d}}\left(0^{+}\right)\right][$Harding et al., 2005]. It is composed of the direct solar beam $\left[\left(E_{d}\right)_{\text {direct }}\right]$ and the diffuse sky irradiance $\left[\left(E_{d}\right)_{\text {diffuse }}\right][$ Gordon, 1989; Kirk, 1994; Mobley, 1994]:

$$
E_{d}=\left(E_{d}\right)_{\text {direct }}+\left(E_{d}\right)_{\text {diffuse }}
$$

If the fraction of the direct solar beam is defined as $f_{\text {direct }}$, then the fraction of diffuse sky irradiance becomes $\left(1-f_{\text {direct }}\right)$.

[9] The direct solar beam, $\left(E_{d}\right)_{\text {direct }}$, originating from the solar zenith angle $\left(\theta_{s}\right)$ is diffracted to $\theta_{w}$ by Snell's Law as it crosses the air-water interface [Mobley, 1994]. As with the Gordon [1989] model, the diffuse attenuation coefficient of the direct solar beam, $\left[K_{d}(z)\right]_{\text {direct }}$, is assumed to vary inversely with $\bar{\mu}_{w}$ :

$$
\left[K_{d}(z)\right]_{\text {direct }}=\frac{\left[K_{d}\left(\theta_{w}=0^{\circ}, z\right)\right]_{\text {direct }}}{\bar{\mu}_{w}}
$$

Here, $\left[K_{d}\left(\theta_{w}=0^{\circ}, z\right)\right]_{\text {direct }}$ represents the diffuse attenuation coefficient of $\left(E_{d}\right)_{\text {direct }}$ when the sun is directly overhead $\left(\theta_{s}=0^{\circ}, \cos \theta_{w}=1, \bar{\mu}_{w}=1\right)$, and closely approximates $\left(a+b_{b}\right)$ at the surface (see equation (7)). $\left[K_{d}\left(\theta_{w}=0^{\circ}, z\right)\right]_{\text {direct }}$ increases with depth as the direct solar beam is scattered by water molecules and suspended particles. Application of the asymptotic theory shown in equation (8) to describe the vertical distribution of $\left[K_{d}\left(\theta_{w}=0^{\circ}, z\right)\right]_{\text {direct }}$ through integra- tion, along with equation (11), provides the average diffuse attenuation coefficient of the direct solar beam:

$$
\left[\bar{K}_{d}(z)\right]_{\text {direct }}=\frac{1}{z} \frac{1}{\bar{\mu}_{w}} \int_{0}^{z}\left\{K_{d}(\infty)+\left[a+b_{b}-K_{d}(\infty)\right] \exp (-P c z)\right\} d z
$$

The integration of equation (12a) results in the following relationship:

$$
\left[\bar{K}_{d}(z)\right]_{\text {direct }}=\frac{1}{\bar{\mu}_{w}}\left\{K_{d}(\infty)+\frac{\left[a+b_{b}-K_{d}(\infty)\right]}{P c z}[1-\exp (-P c z)]\right\}
$$

Thus, the relative vertical distribution of $\left(E_{d}\right)_{\text {direct }}$ is calculated as:

$$
\begin{aligned}
\frac{\left[E_{d}(z)\right]_{\text {direct }}}{E_{d}\left(0^{-}\right)}= & f_{\text {direct }} \exp \left\{-\frac{K_{d}(\infty) \times z}{\bar{\mu}_{w}}-\frac{\left[a+b_{b}-K_{d}(\infty)\right]}{\bar{\mu}_{w} P c}\right. \\
& \cdot[1-\exp (-P c z)]\}
\end{aligned}
$$

The average cosine of the diffuse sky downwelling irradiance above the water, $\left[\bar{\mu}_{d}\left(0^{+}\right)\right]_{\text {diffuse }}$, is highly variable from 0.25 when the sun is nearly horizontal $\left(\theta_{s}=89^{\circ}\right)$, in which condition irradiance arriving the water surface is almost diffused and whose irradiance angular characteristics are similar to those at cloudy or misty days, to 0.54 when the sun is directly overhead $\left(\theta_{s}=0^{\circ}\right)$ (Figure 1). Snell's Law, however, constrains the inwater value of $\left[\bar{\mu}_{d}\left(0^{-}\right)\right]_{\text {diffuse }}$ to 0.69 when $\theta_{s}=$ $89^{\circ}$ and 0.78 when $\theta_{s}=0^{\circ}$ (Figure 1). Exact radiative transfer modeling has shown that the asymptotic value of the average cosine of downwelling irradiance $\left[\bar{\mu}_{d}(\infty)\right]$ in natural waters is relatively constant at about 0.7 [Kirk, 1994; Mobley, 1994]. Thus, the vertical variation of $\left[\bar{\mu}_{d}(z)\right]_{\text {diffuse }}$ ranges only from $\sim 0.78$ to $\sim 0.7$, and is relatively insensitive to both depth and the solar zenith angle $\left(\theta_{s}\right)$. Thus, the diffuse sky irradiance is simply calculated as:

$$
\frac{\left[E_{d}(z)\right]_{\text {diffuse }}}{E_{d}\left(0^{-}\right)}=\left(1-f_{\text {direct }}\right) \exp \left(-K_{\text {diffise }} z\right)
$$

Equations (13) and (14) provide a general basis to determine the relative vertical distribution of $E_{d}(z)$ :

$$
\begin{aligned}
\frac{E_{d}(z)}{E_{d}\left(0^{-}\right)}= & f_{\text {direct }} \exp \left\{-\frac{K_{d}(\infty) \times z}{\bar{\mu}_{w}}-\frac{\left[a+b_{b}-K_{d}(\infty)\right]}{\bar{\mu}_{w} P c}\right. \\
& \cdot[1-\exp (-P c z)]\}+\left(1-f_{\text {direct }}\right) \exp \left(-K_{\text {diffuse }} z\right)
\end{aligned}
$$

\section{Application}

\subsection{Hydrolight Simulations}

[10] Provided with the knowledge of IOPs $\left(a, b, b_{b}\right.$, and $\left.c\right)$ and light field geometry $\left(\theta_{s}\right.$ and $\left.\bar{\mu}_{w}\right)$, the unparameterized variables in equation (15) include $f_{\text {direct }}, K_{d}(\infty), P$, and $K_{\text {diffuse }}$. Hydrolight v4.2 was used here to derive the relationships between these parameters and measurable or derivable water and atmospheric properties (e.g., $a, b, c, b_{b}, \theta_{s}$, cloud coverage, and so on). The default models and the input para- 
Table 1. Default Models and the Input Conditions for Hydrolight Runs

\begin{tabular}{|c|c|}
\hline Quantity & Range or Models \\
\hline \multicolumn{2}{|c|}{ Atmospheric conditions } \\
\hline Sky model & $\begin{array}{l}\text { RADTRAN [Gregg and Carder, } \\
\text { 1990; Harrison and } \\
\text { Coombes, 1988] }\end{array}$ \\
\hline Atmospheric pressure & $1.013 \times 10^{5} \mathrm{~Pa}$ \\
\hline Horizontal visibility & $15 \mathrm{~km}$ \\
\hline Relative humidity & $80 \%$ \\
\hline Precipitable water content & $2.5 \mathrm{~cm}$ \\
\hline Total ozone concentration & 300 Dobson \\
\hline Wind speed (WS) & $5 \mathrm{~m} \mathrm{~s}^{-1}$ \\
\hline Solar zenith angle $\left(\theta_{s}\right)$ & $0^{\circ}$ to $89^{\circ}$ \\
\hline Wavelength $(\lambda)$ & 350 to $700 \mathrm{~nm}$ \\
\hline Air ma & Marine \\
\hline Cloud coverage & 0 to $100 \%$ \\
\hline \multicolumn{2}{|c|}{ Water conditions (vertically homogeneous) } \\
\hline Single scattering albedo $\left(\omega_{0}\right)$ & 0.1 to 0.9 \\
\hline Backscattering ratio $\left(b_{b} / b\right)$ & 0.005 to 0.5 \\
\hline Scattering phase function & $\begin{array}{l}\text { Petzold [1972] and Fourier-Forand } \\
\text { function [Mobley et al., 2002] }\end{array}$ \\
\hline \multicolumn{2}{|c|}{ Hydrolight default classic Case 1 IOP model } \\
\hline Water absorption $\left(a_{w}\right)$ & Pope and Fry [1997] \\
\hline [Chl] & 0 to $10 \mathrm{mg} \mathrm{m}^{-3}$ \\
\hline Particulate absorption $\left(a_{p}\right)$ & Prieur and Sathyendranath [1981 \\
\hline CDOM absorption $\left(a_{g}\right)$ & Morel and Gentili [1991] \\
\hline Scattering by pure seawater $\left(b_{w}\right)$ & Smith and Baker [1981] \\
\hline Particulate scattering $\left(b_{p}\right)$ & Gordon and Morel [1983] \\
\hline Backscattering ratio $\left(b_{b p} / b_{p}\right)$ & 0.01833 \\
\hline Scattering phase function & Petzold [1972] \\
\hline
\end{tabular}

meters used to calculate the atmospheric and water conditions are provided in Table 1. Values for the unparameterized variables in equation (15) were derived from Hydrolight simulations using single scattering albedos $\left(\omega_{0}=b / c\right)$ ranging from 0.1 to 0.9 in interval of 0.1 and various scattering phase functions including Petzold's [1972] average $\left(b_{b} / b=\right.$ 0.01833 ) and the Fournier-Forand scattering phase function $\left(b_{b} / b=0.005\right.$ to 0.5$)$ [Mobley et al., 2002].

[11] A special set of runs were calculated with $\theta_{s}=89^{\circ}$ (near horizontally), under which $\left(E_{d}\right)_{\text {direct }}$ approached zero. Thus, $K_{\text {diffuse, }}$ which is almost independent of depth and $\theta_{s}$, was directly calculated from the simulated results of $E_{d}(z)$ at $\theta_{s}=89^{\circ}$ by the nonlinear least square match method of TableCurve 2D v5.01 (SYSTAT Software Inc.). The water column beneath the euphotic zone, defined as $E_{d}(z) / E_{d}\left(0^{-}\right)<$ $1 \%$, was not considered in these simulations.

[12] Parameterizations of $f_{\text {direct }}$ and $K_{d}(\infty)$ were calculated directly from Hydrolight results. $K_{d}(\infty)$ depends only on water IOPs, while $f_{\text {direct }}$ is a function of the above-water conditions (here $\theta_{s}$ and cloud coverage). $\left[E_{d}(z)\right]_{\text {direct }}$ was calculated from equation (15) by subtracting the fraction of the diffuse source. The exponential slope $(P)$ was calculated from equation (12) by nonlinear least square method from TableCurve 2D v5.01 (SYSTAT Software Inc.). The relationships for these four unparameterized variables were derived from full suite of Hydrolight simulations as described above, and the results will be presented in detail in section 4.1.

[13] PZ06 (equation (15)) was also compared to Hydrolight simulations, G89 (equation (2)), and K91 (equation (4)) by using typical Case 1 IOP conditions (Table 1). Fidelity of PZ06 (equation (15)), G89 (equation (2)), or K91 (equation (4)) $\left(\mathrm{C}_{\mathrm{i}}\right)$ to Hydrolight $\left(\mathrm{C}_{\mathrm{HL}}\right)$ was evaluated by calculating the percent root mean square error $\left[(\mathrm{RMSE})_{\mathrm{i}}\right]$ between their results.

$$
(R M S E)_{i}=\left[\frac{1}{n} \sum\left(C_{i} / C_{H L}-1\right)^{2}\right]^{1 / 2} \times 100 \%
$$

\subsection{Global In Situ Data in Validating $K_{d}$ Prediction}

[14] The global in situ measurements from the NASA bioOptical Marine Algorithm Data set (NOMAD; version 2.0 $\alpha$ ) [Werdell and Bailey, 2005] were used to validate our approach in predicting $\bar{K}_{d}(z)$ down to 1 optical depth $\left(K_{1 o z}\right.$, where $\left.K_{1 o z} \times z=1\right)$. NOMAD includes coincident data set of $K_{1 o z}$, chlorophyll $a$ concentration ([Chl]), and $b_{b}$. The coincident near-surface spectrophotometer (WET Labs, Inc.) measurements of absorption coefficient $(a)$, scattering coefficient $(b)$, and beam attenuation coefficient $(c)$ were downloaded from the SeaWiFS Bio-optical Archive and Storage System (SeaBASS). Finally, 115 stations, of which 75 from Plumes and Blooms cruises (PB) during January 2001 and February 2003, 21 from ACE-Asia cruise during March and April 2001 (RB-01-02), and 19 from the JapanEast Sea cruise during July 1999 (JES-1999), were included in this paper [Werdell and Bailey, 2005]. The solar zenith angle for each station based on the information of year, date, time, longitude, and latitude was calculated from IDL codes adopted from Ocean Color IDL library (http://oceancolor. gsfc.nasa.gov/cgi/idllibrary.cgi). The sky was assumed to be clear if no information of cloud coverage was provided. PZ06 (equation (15)) was used to calculate $K_{1 o z}$ by solving equation (15) with the inputs of field IOPs and sky conditions. Model performance at selected wavelengths (412, 443, 490, 510, and $555 \mathrm{~nm}$ ) was evaluated by the RMSE. However, the obvious unmatched measurements defined as $K_{d}<a$ or $K_{d}>2\left(a+b_{b}\right)$ were excluded for analysis in this paper. The comparisons to G89 (equation (2)) and K91 (equation (4)), which were calculated from the inputs of field IOPs and solar zenith angles, and the S09 operational algorithm (equation (9)), which was calculated from the field measurements of remote sensing reflectance $\left(R_{r s}\right)$, were also shown.

\subsection{Validating the Vertical Distribution of $E_{d}(z) / E_{d}\left(0^{-}\right)$ Against Field Observations in the SMAB}

[15] Bio-optical observations made in the southern Middle Atlantic Bight (SMAB) on 18 May 2005 were used to validate the PZ06 (equation (15)) predictions of the vertical distribution of $E_{d}(z) / E_{d}\left(0^{-}\right)$. The SMAB is well recognized as typical river-driven coastal waters where colored dissolved organic matter (CDOM) and detritus, along with phytoplankton and pure water, contribute significantly to bio-optical properties [Mannino et al., 2008; Pan et al., 2008]. The selected stations were located near Cape Henry (Station $2 ;-75.88^{\circ} \mathrm{W}, 36.91^{\circ} \mathrm{N}$ ) and $\sim 6.5 \mathrm{~km}$ east of the Chesapeake Light Tower (Station $6 ;-75.64^{\circ} \mathrm{W}, 36.92^{\circ} \mathrm{N}$ ). Profiles of $E_{d}(z)$ were collected with a HyperPro II hyperspectral radiometric system (Satlantic, Inc.) at $5 \mathrm{~nm}$ intervals from 350 to $800 \mathrm{~nm}$. Vertical profiles of absorption coefficient $(a)$ and beam attenuation coefficient $(c)$ were measured with an $a c-9$ spectrophotometer (WET Labs, Inc.). The scattering coefficient $(b)$ was calculated as $b=c-a$. 


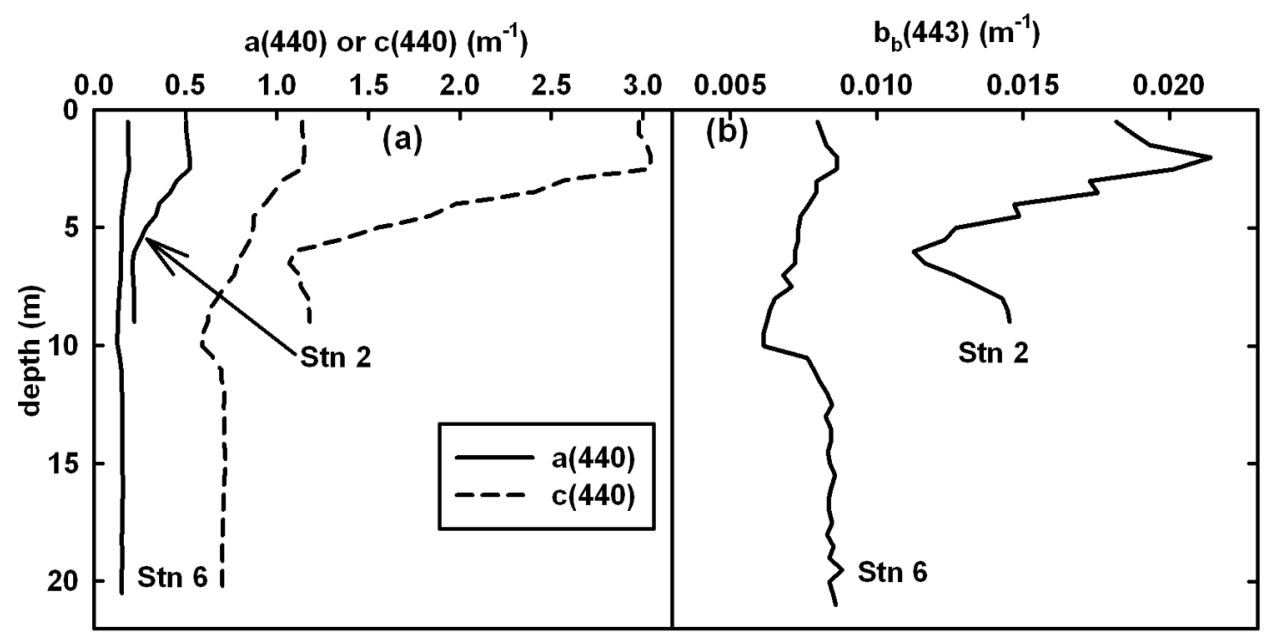

Figure 2. Vertical profiles of (a) absorption coefficient at $440 \mathrm{~nm}[a(440)]$ and beam attenuation coefficient at $440 \mathrm{~nm}[c(440)]$ and (b) backscattering coefficient at $443 \mathrm{~nm}\left[b_{b}(443)\right]$ for Station $2\left(-75.88^{\circ} \mathrm{W}\right.$, $\left.36.91^{\circ} \mathrm{N}\right)$ and Station $6\left(-75.64^{\circ} \mathrm{W}, 36.92^{\circ} \mathrm{N}\right)$.

Backscattering coefficient $\left(b_{b}\right)$ profiles were measured with a Hydroscat-6 (HOBI Labs, Inc.). All measurements were averaged to $0.5 \mathrm{~m}$ depth bins except for the HyperPro radiometer for which the records of $E_{d}$ at the exact depth points were used. To remove uncertain boundary effects caused by high turbidity close to the seafloor or by touching the seafloor with some instruments, all measurements were at least $3 \mathrm{~m}$ above the seafloor. All data below the euphotic zone, where $E_{d}(z) / E_{d}\left(0^{-}\right)<1 \%$, were excluded. Both stations were optically deep as $<10 \%$ of $E_{d}\left(0^{-}\right)$reached the seafloor, even though their geometric bottom depths were $10 \mathrm{~m}$ and $21 \mathrm{~m}$ for Stations 2 and 6, respectively. Station 2 was more estuarine in character (surface salinity $\approx 22 \mathrm{psu}$ ) and more turbid $\left([\mathrm{Chl}]=5.4\right.$ and $1.9 \mathrm{mg} \mathrm{m}^{-3}$ at surface and bottom; higher $a, c$, and $b_{b}$ ) (Figure 2). Station 6 was more marine in character (surface salinity $\approx 28 \mathrm{psu}$ ) and less turbid $\left([\mathrm{Chl}]=1.0,0.6\right.$, and $1.1 \mathrm{mg} \mathrm{m}^{-3}$ at surface, middle, and bottom; lower $a, c$, and $b_{b}$ ) (Figure 2). The solar zenith angles $\left(\theta_{s}\right)$ of Stations 2 and 6 calculated from Hydrolight simulations based on local date, time, longitude, and latitude were $40.9^{\circ}$ and $23.1^{\circ}$, respectively. Five common wavelengths $(440,488,510,555$, and $676 \mathrm{~nm})$ measured by the $a c-9$ and Hydroscat -6 spanning almost the entire range of photosynthetically active radiation (PAR; 400 to $700 \mathrm{~nm}$ ) were selected for analysis. Measurements at $488 \mathrm{~nm}$ were assumed equal to those at $490 \mathrm{~nm}$. As before, model performance was evaluated by RMSE.

\subsection{Satellite Imagery}

[16] The observations from SeaWiFS at the SMAB with latitude from $36^{\circ} \mathrm{N}$ to $39.5^{\circ} \mathrm{N}$ and longitude from $-77^{\circ} \mathrm{W}$ to $-74^{\circ} \mathrm{W}$ were processed from Level 1 to Level 2 using the SeaWiFS Data Analysis System software (SeaDAS version 6.0), including the products of remote sensing reflectance $\left(R_{r s}\right)$, diffuse attenuation coefficient at $490 \mathrm{~nm}$ estimated from equation (9) $\left(K_{490} \_\right.$S09), and solar zenith angle $\left(\theta_{s}\right)$. Absorption coefficients of phytoplankton $\left(a_{p h}\right)$ and CDOM plus nonpigmented particles $\left(a_{d g}\right)$ were estimated from empirical algorithms based on $R_{r s}$ ratios as described by Pan et al. [2008]. The total absorption coefficient was then calculated as $a=a_{p h}+a_{d g}+a_{w}$, while the spectral absorption coefficients of pure water were adapted from Pope and Fry [1997]. Backscattering coefficients $\left(b_{b}\right)$ were estimated by solving equation (17) [Gordon et al., 1988] with satellite $R_{r s}$ observations and the estimated absorption coefficients $(a)$.

$$
\frac{R_{r s}(\lambda)}{0.526} \approx 0.0949 \frac{b_{b}(\lambda)}{a(\lambda)+b_{b}(\lambda)}+0.0794\left[\frac{b_{b}(\lambda)}{a(\lambda)+b_{b}(\lambda)}\right]^{2}
$$

The particulate backscattering coefficient $\left(b_{b p}\right)$ was then estimated as $b_{b p}=b_{b}-b_{b w}$. Scattering coefficients of pure water $\left(b_{w}\right)$ were adapted from Smith and Baker [1981], while forward and backward scattering was assumed isotropic resulting in $b_{b w}=0.5 b_{w}$. Particulate scattering coefficient $\left(b_{p}\right)$ was estimated from the relationships between $b_{b p}$ and $b_{p}$ in this region as described by (X. Pan et al., manuscript in preparation, 2010):

$$
\begin{aligned}
& \text { September-April }: b_{p}(490) \\
& =-2.015+\left[4.061+362.5 b_{b p}(490)\right]^{0.5} \\
& \text { May-August }: b_{p}(490)=97.09 b_{b p}(490)
\end{aligned}
$$

Total scattering coefficient $(b)$ was then estimated as $b=b_{p}+$ $b_{w}$, and beam attenuation coefficient $(c)$ was calculated as $c=$ $a+b$.

[17] The sky was assumed to be clear for each pixel. The average $K_{d}(490)$ from the surface to one optical depth calculated from PZ06 model (K490_PZ06) by solving equation (15) was compared to the results from S09 algorithm (equation (9)).

\section{Results}

\subsection{Derived Coefficients}

[18] On the basis of Hydrolight simulations (see the details in section 3.1), parameters containing in the PZ06 

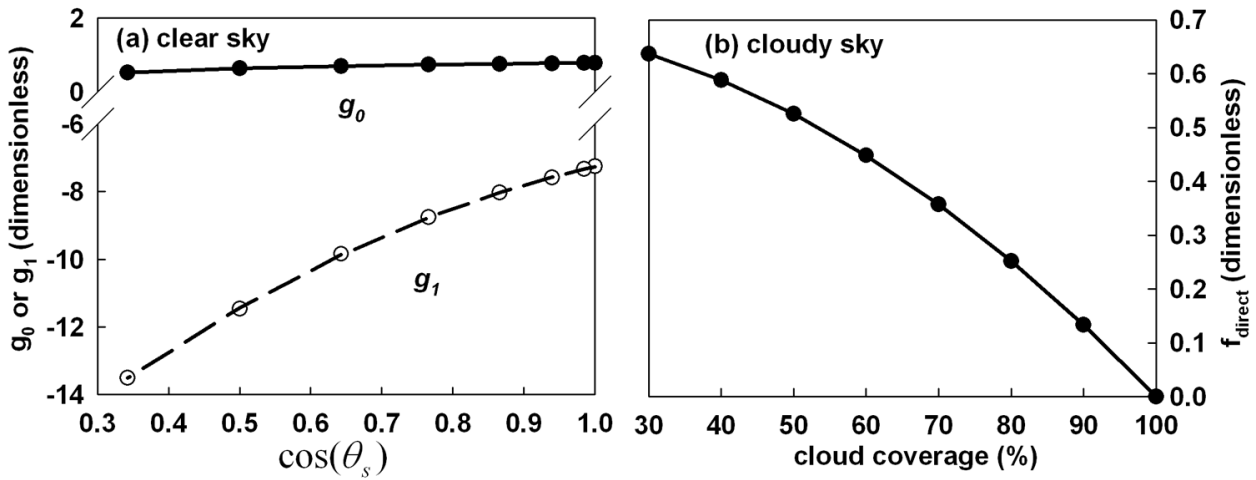

Figure 3. (a) The relationships between the derived coefficients $\left(g_{0}\right.$ and $\left.g_{1}\right)$ and solar zenith angle $\left(\theta_{s}\right)$ for a clear sky. (b) Dependence of the fraction of direct solar beam, $f_{\text {direct }}$, on cloud coverage. Simulated results are indicated by data points connected by regression lines.

model (equation (15)) can be specified to the measurable sky and water conditions. For clear sky conditions (e.g., cloud coverage $<30 \%$ ), the fraction of direct solar irradiance $\left(f_{\text {direct }}\right)$ was described by an exponential function of wavelength $\left(\mathrm{r}^{2}>0.99, \mathrm{P}<0.001\right)$ :

$$
f_{\text {direct }}(\lambda ; \text { clear })=g_{0}+g_{1} \exp (-0.01 \lambda)
$$

Here $g_{0}$ and $g_{1}$ were significantly $\left(\mathrm{r}^{2}>0.99, \mathrm{P}<0.001\right)$ related to the solar zenith angle $\left(\theta_{s}\right)$ (Figure $3 \mathrm{a}$ ):

$$
\begin{gathered}
g_{0}=1.147-0.363\left(\cos \theta_{s}\right)^{-0.5} \\
g_{1}=-19.25\left(1-\cos \theta_{s}\right)-7.26\left(\cos \theta_{s}\right)^{2}
\end{gathered}
$$

When cloud coverage was over $30 \%, f_{\text {direct }}$ became independent of wavelength $(\lambda)$ and $\theta_{s}$, but was significantly $\left(\mathrm{r}^{2}>\right.$ $0.99, \mathrm{P}<0.001)$ related to the cloud cover $(\%$ cloud $)$ (Figure $3 \mathrm{~b})$ :

$$
f_{\text {direct }}(\text { cloudy })=0.7 \times\left(1-\% \text { cloud }^{2}\right)
$$

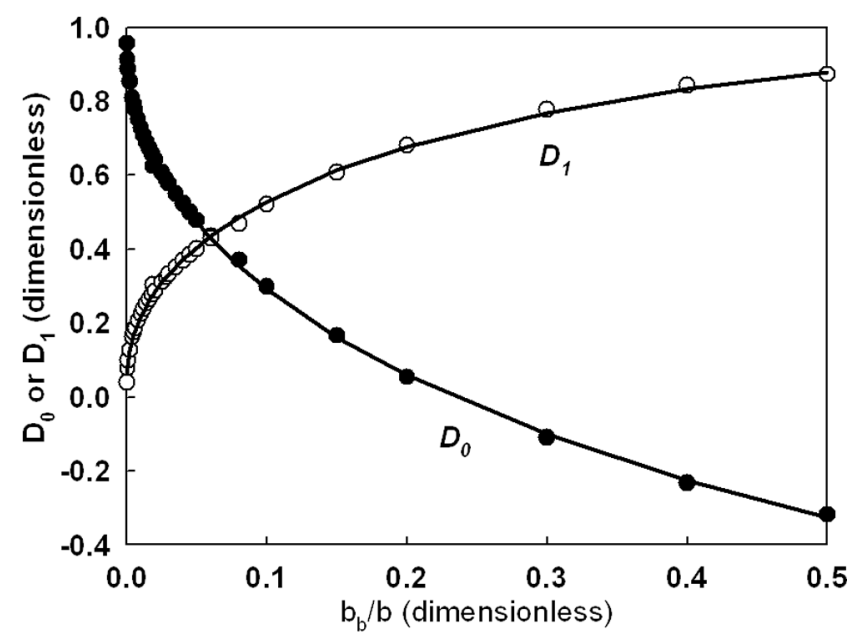

Figure 4. Dependence of the derived coefficients $\left(D_{0}\right.$ and $\left.D_{1}\right)$ on the backscattering ratio $\left(b_{b} / b\right)$. Simulated results are indicated by data points connected by regression lines.
The asymptotic diffuse attenuation coefficient $\left[K_{d}(\infty)\right]$ was described by a second-order polynomial function $\left(\mathrm{r}^{2}>0.99\right.$ except when $b_{b} / b>0.3$ in which $\left.\mathrm{r}^{2}>0.97, \mathrm{P}<0.001\right)$ :

$$
K_{d}(\infty)=\left(1-D_{0} \omega_{0}-D_{1} \omega_{0}^{2}\right) \times c
$$

Here $\omega_{0}$ is the single scattering albedo $(=b / c) . D_{0}$ and $D_{1}$ were significantly $\left(\mathrm{r}^{2}>0.99, \mathrm{P}<0.001\right)$ related to the backscattering ratio $\left(b_{b} / b\right)$ (Figure 4$)$ :

$$
\begin{aligned}
& D_{0}=0.959-2.346\left(b_{b} / b\right)^{0.5}+0.747\left(b_{b} / b\right) \\
& D_{1}=0.046+1.807\left(b_{b} / b\right)^{0.5}-0.888\left(b_{b} / b\right)
\end{aligned}
$$

Similar to $K_{d}(\infty)$, the diffuse attenuation coefficient of the diffuse incident beam $\left(K_{\text {diffuse }}\right)$ was described by another polynomial function $\left(\mathrm{r}^{2}>0.99, \mathrm{P}<0.001\right)$ :

$$
K_{\text {diffuse }}=\left(1.317-A_{0} \omega_{0}-A_{1} \omega_{0}^{2}\right) \times c
$$

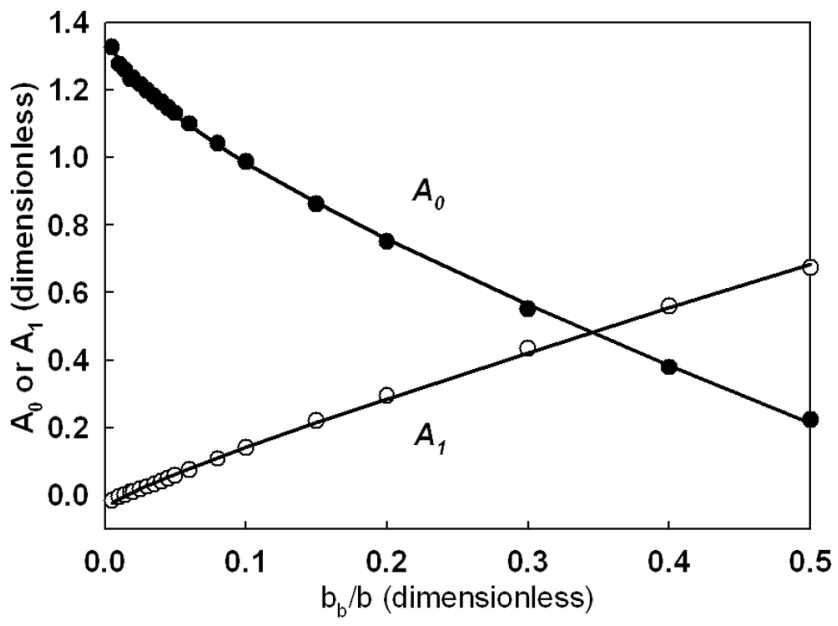

Figure 5. Dependence of the derived coefficients $\left(A_{0}\right.$ and $\left.A_{1}\right)$ on the backscattering ratio $\left(b_{b} / b\right)$. Simulated results are indicated by data points connected by regression lines. 


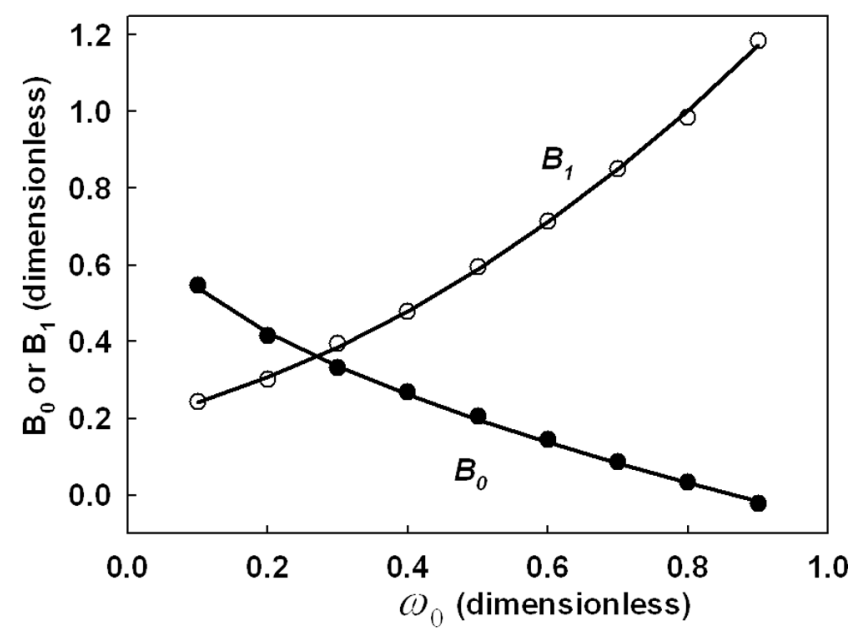

Figure 6. Dependence of the derived coefficients $\left(B_{0}\right.$ and $\left.B_{1}\right)$ on the single scattering albedo $\left(\omega_{0}\right)$. Simulated results are indicated by data points connected by regression lines.

Similarly $A_{0}$ and $A_{1}$ were significantly $\left(\mathrm{r}^{2}>0.99, \mathrm{P}<0.001\right)$ related to the backscattering ratio $\left(b_{b} / b\right)$ (Figure 5):

$$
\begin{aligned}
& A_{0}=1.399-1.012\left(b_{b} / b\right)^{0.5}-0.939\left(b_{b} / b\right) \\
& A_{1}=-0.047+0.244\left(b_{b} / b\right)^{0.5}+1.120\left(b_{b} / b\right)
\end{aligned}
$$

The exponential slope $(P)$ describing the vertical variation of $K_{d}\left(\theta_{w}=0^{\circ}, z\right)$ was significantly $\left(\mathrm{r}^{2}>0.95, \mathrm{P}<0.001\right)$ related to the backscattering ratio $\left(b_{b} / b\right)$ :

$$
P=B_{0}+B_{1}\left(b_{b} / b\right)^{0.5}
$$

Here the coefficients $B_{0}$ and $B_{1}$ were significantly $\left(\mathrm{r}^{2}>0.99, \mathrm{P}<\right.$ $0.001)$ related to the single scattering albedo $\left(\omega_{0}\right)$ (Figure 6):

$$
\begin{gathered}
B_{0}=0.817-0.877 \omega_{0}^{0.5} \\
B_{1}=0.193+0.421 \omega_{0}+0.741 \omega_{0}^{2}
\end{gathered}
$$

\subsection{Verification Against Hydrolight Simulations of $E_{d}(z) / E_{d}\left(0^{-}\right)$}

[19] The parameter values derived from Hydrolight simulations were applied to equation (15) to calculate $E_{d}(z) /$ $E_{d}\left(0^{-}\right)$. In general, PZ06 (equation (15)) yielded estimates that were within 2 to $4 \%$ RMSE of the Hydrolight simulations for a wide range of [Chl] and $\theta_{s}$ (Figure 7a). Model accuracy decreased as the water column optical density increased (e.g., more particles and [Chl]) (Figure 7a). There was no consistent relationship with solar zenith angle (Figure 7a). G89 model (equation (2)) predicted $E_{d}(z) / E_{d}\left(0^{-}\right)$ with an RMSE just below $10 \%$ for clearer waters (e.g., [Chl] < $1 \mathrm{mg} \mathrm{m}^{-3}$ ), and rose to nearly $80 \%$ as optical density increased (e.g., $[\mathrm{Chl}]=10 \mathrm{mg} \mathrm{m}^{-3}$ ) (Figure 7b). Under particle-rich conditions, the G89 model (equation (2)) became increasingly sensitive to solar zenith angle (Figure $7 \mathrm{~b}$ ) because increasing $\theta_{s}$ increased the fraction of the diffuse

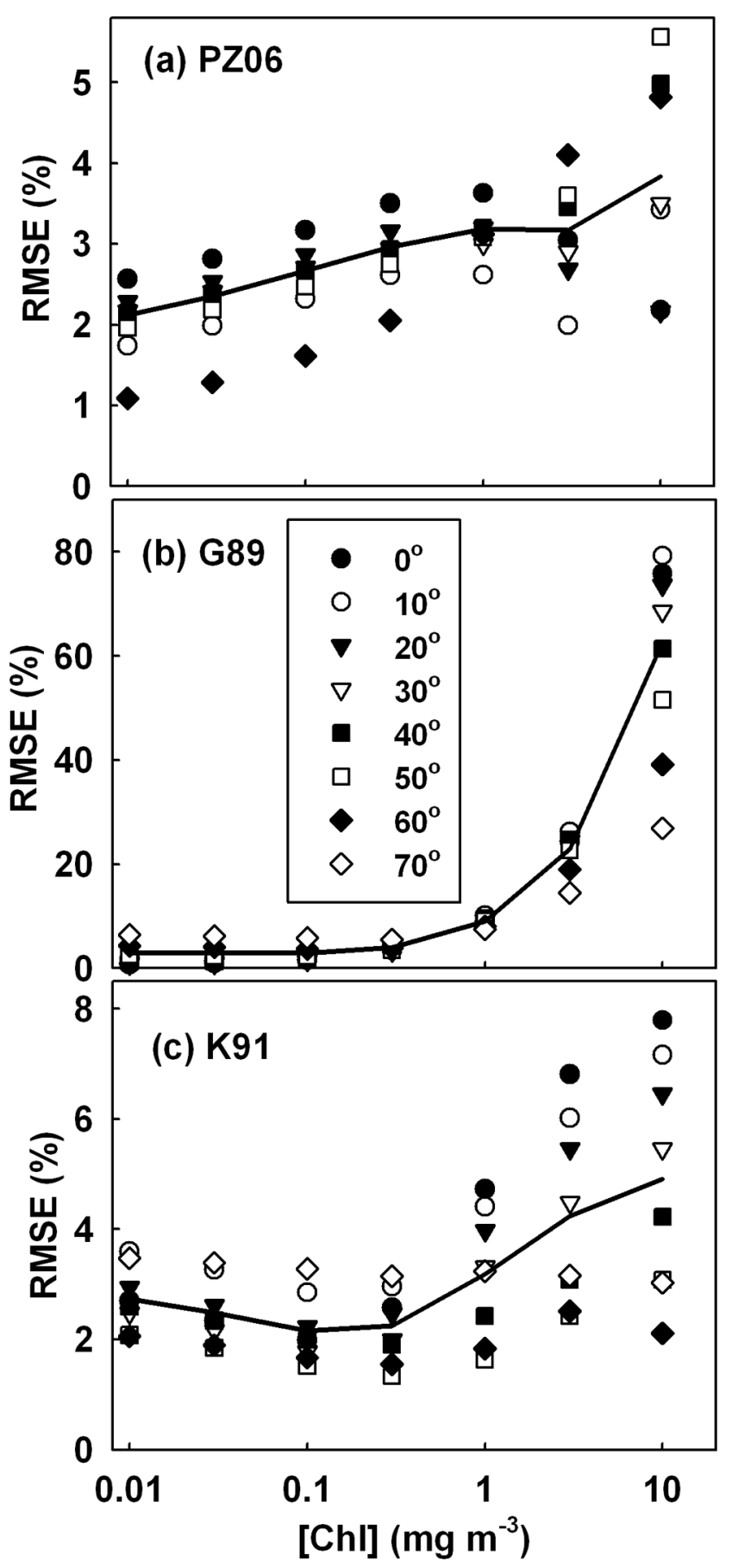

Figure 7. The root mean square error (RMSE) of $E_{d}(z) /$ $E_{d}\left(0^{-}\right)$for (a) PZ06 (equation (15)), (b) G89 model (equation (2)), and (c) K91 model (equation (4)) against Hydrolight simulations generated from the inputs of water condition as described in Table 1 . Symbols indicate $\theta_{s}$ ranging from 0 to $70^{\circ}$ and averaged for all wavelengths $(350-650 \mathrm{~nm})$ for each $\theta_{s}$. Water IOPs were Case 1 with [Chl] $=0.01$ to $10 \mathrm{mg} \mathrm{m}^{-3}$ for a $10 \mathrm{~m}$ water column. Solid lines: average RMSE for all solar zenith angles and all wavelengths. 


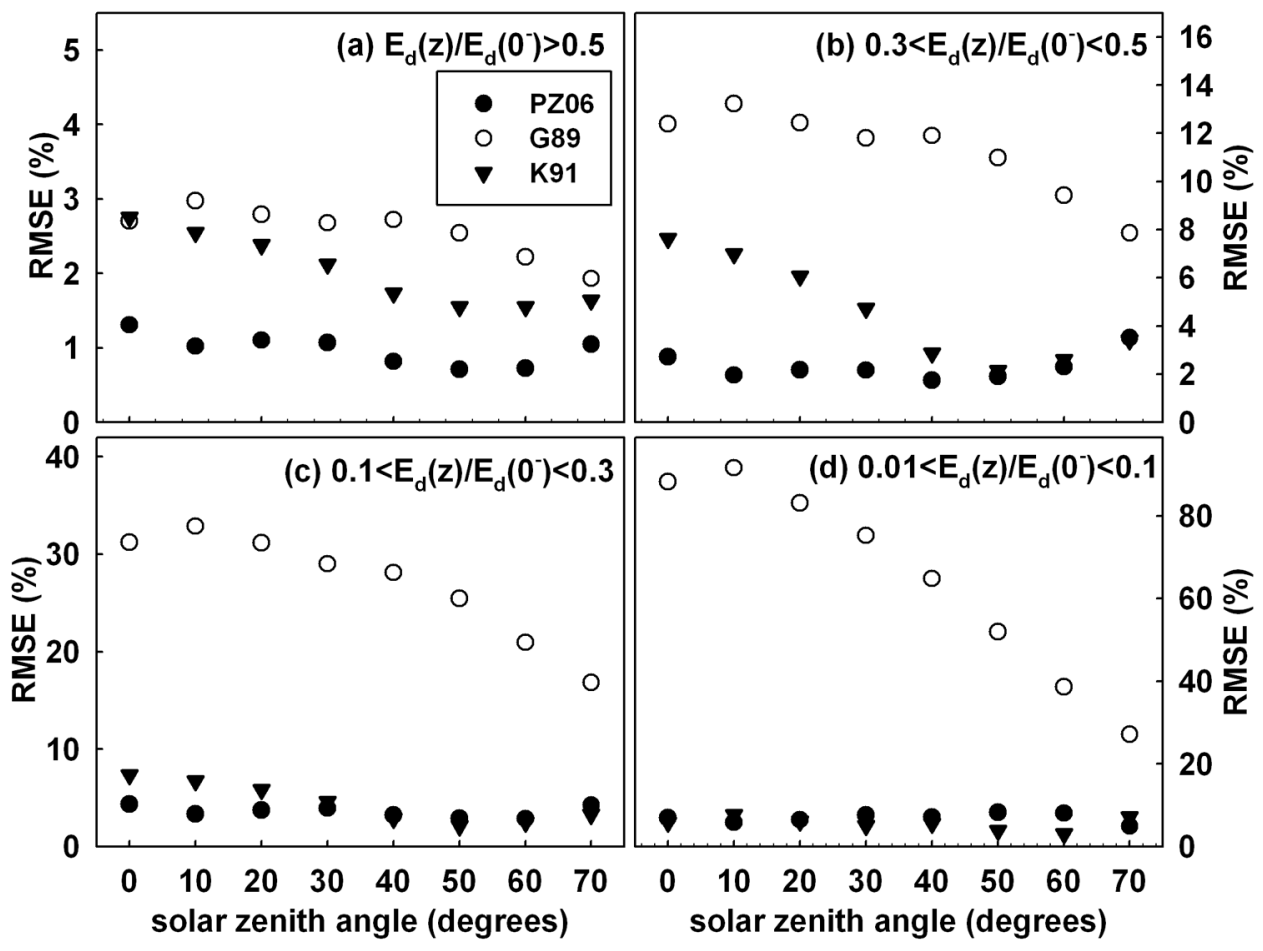

Figure 8. The RMSE of model performance in estimating $E_{d}(z) / E_{d}\left(0^{-}\right)$within the layer of (a) $E_{d}(z) /$ $E_{d}\left(0^{-}\right)>0.5$, (b) $0.3<E_{d}(z) / E_{d}\left(0^{-}\right)<0.5$, (c) $0.1<E_{d}(z) / E_{d}\left(0^{-}\right)<0.3$, and (d) $0.01<E_{d}(z) / E_{d}\left(0^{-}\right)<$ 0.1 for the models of PZ06 (equation (15)), G89 (equation (2)), and K91 (equation (4)) against Hydrolight simulations generated from the inputs of water condition as described in Table 1. Symbols indicate for $[\mathrm{Chl}]=0$ to $10 \mathrm{mg} \mathrm{m}^{-3}$ and for all wavelengths $(350-650 \mathrm{~nm})$.

incident solar beam whose diffuse attenuation coefficient $\left(K_{\text {diffuse }}\right)$ was less sensitive to depth. Both depending on the statistical analyses of radiative transfer simulations, Kirk [1991] model (K91; equation (4)) showed similar RMSE to our approach $(2.65 \pm 0.79 \%$ versus $2.44 \pm 0.69 \%)$ for relatively low particle conditions (e.g., [Chl] $\leq 1 \mathrm{mg} \mathrm{m}^{-3}$ ), but a little higher RMSE $(4.58 \pm 1.88 \%$ versus $3.39 \pm 1.04 \%)$ for relatively optically turbid waters (e.g., $[\mathrm{Chl}]=3$ and $10 \mathrm{mg} \mathrm{m}^{-3}$ ) because of the impact of increasing scattering on radiative distributions (Figure 7c). PZ06 model (equation (15)) is competitive to G89 (equation (2)) or K91 (equation (4)) models, regardless of the optically upper layer (e.g., above the depth receiving $30 \%$ of surface irradiance) or optically lower layer (e.g., between the depths receiving 30\% and $1 \%$ of surface irradiance) (Figures 8a-8d). In general, all of these three models increase their relative errors in reproducing $E_{d}(z) / E_{d}\left(0^{-}\right)$as the increase of optical depth, especially for G89 model (equation (2)) (Figures 8a-8d). Although K91 model (equation (4)) performs similar RMSE to our model, its relative higher errors in producing $E_{d}(z) / E_{d}\left(0^{-}\right)$for the optically upper layer (Figures $8 \mathrm{a}-8 \mathrm{~d}$ ), however, will cause much higher absolute errors of $E_{d}(z) / E_{d}\left(0^{-}\right)$for the optically upper layer.

\subsection{Validation Against NOMAD In Situ Observations of $\boldsymbol{K}_{490}$}

[20] All of four models, PZ06 (equation (15)), G89 (equation (2)), K91 (equation (4)), and S09 (equation (9)), reproduced $K_{490}$ well, as compared to global in situ observations (Figure 9). The RMSE for PZ06 (equation (15)) was $15.6 \%$ at $490 \mathrm{~nm}$, as compared to $14.9 \%, 22.2 \%$, and $15.4 \%$ from G89 (equation (2)), K91 (equation (4)), and S09 (equation (9)) models. S09 model (equation (9)) seemed to produce $K_{490}$ well at clearer water condition (e.g., $\mathrm{K}_{490}<$ $0.15 \mathrm{~m}^{-1}$ ), while tended to contain more uncertainty at more turbid water condition (Figure 9). Compared to the original performance of the operational algorithm by Mueller [2000],

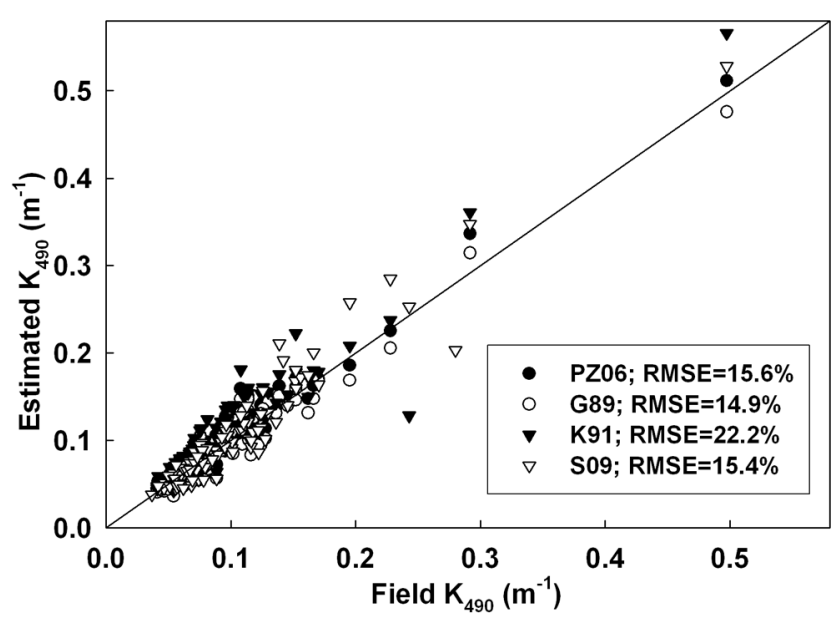

Figure 9. Comparisons of the average diffuse attenuation coefficient from surface to 1 optical depth at $490 \mathrm{~nm}$ $\left(K_{490}\right)$ between NOMAD in situ measurements and estimations from PZ06 (equation (15)), G89 (equation (2)), K91 (equation (4)), and S09 (equation (9)) models. 

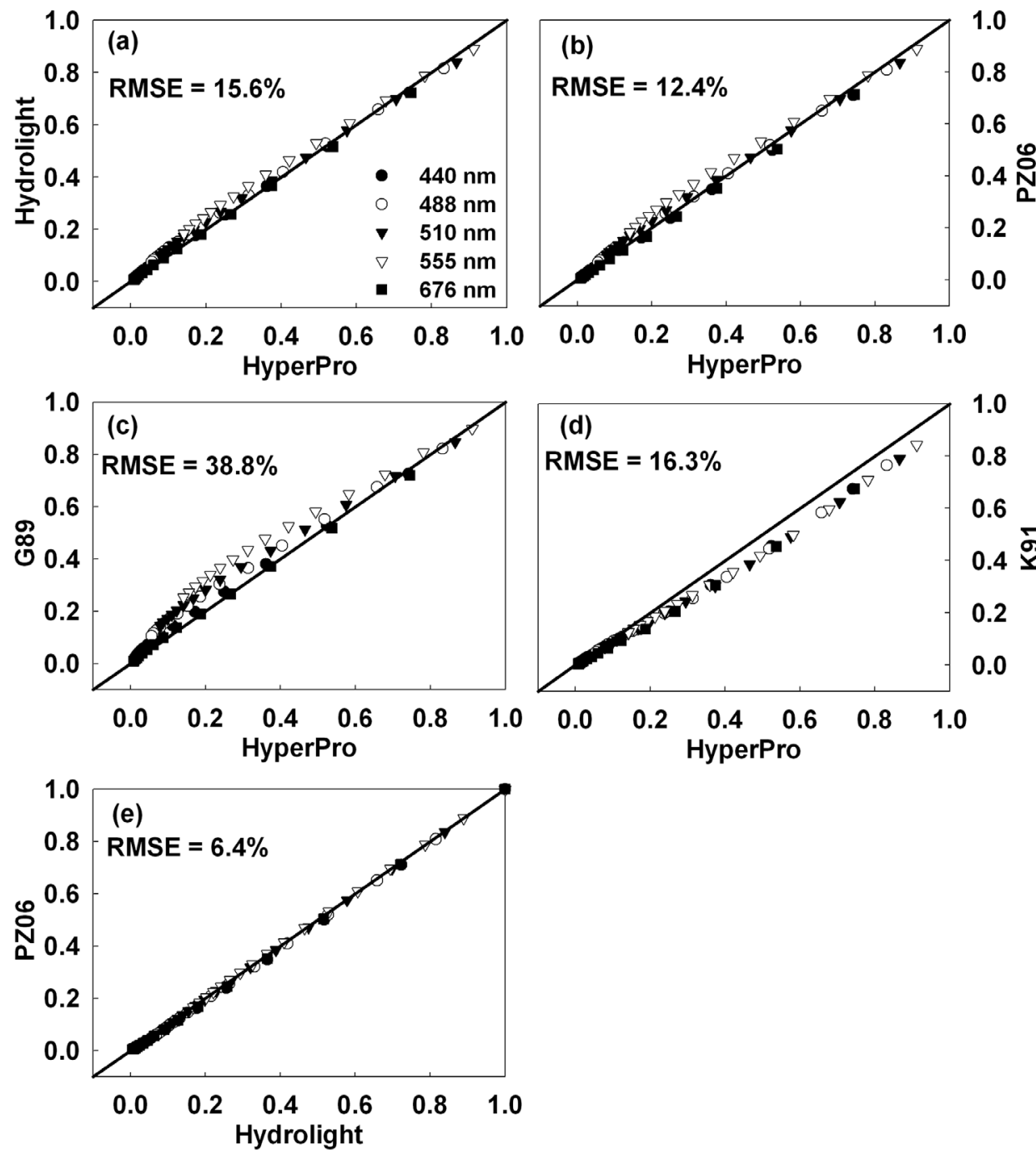

Figure 10. Comparisons of $E_{d}(z) / E_{d}\left(0^{-}\right)$for Station 2: HyperPro observations compared with (a) Hydrolight simulations and estimates by (b) PZ06 (equation (15)), (c) G89 (equation (2)), and (d) K91 (equation (4)) models. (e) Comparison between Hydrolight simulations and PZ06 (equation (15)) estimates. For each symbol, comparisons for multiple depths from the surface to the depth with $1 \%$ of surface irradiance were shown.

the coefficient of 0.016 in S09 (equation (9)) was intentionally embedded to reduce the underestimation of $K_{490}$ for clear waters. Such an intention, however, increases more uncertainty in estimating $K_{490}$ for more turbid waters (Figure 9). G89 model (equation (2)) had typically lower estimation of $K_{490}$ than PZ06 (equation (15)) since it did not consider the scattering effect (Figure 9). K91 model (equation (4)) had typically higher estimation of $K_{490}$ than the field measurements and those from our model (Figure 9). Part of the difference may be accounted by the expressions of $K_{490}$ from different models used in Figure 9: NOMAD and PZ06 (equation (15)) calculated the average $K_{490}$ within one optical depth (from the surface to the depth receiving $\sim 37 \%$ of surface irradiance), while K91 (equation (4)) calculated the average $K_{490}$ within the euphotic layer (from the surface to the depth receiving $1 \%$ of surface irradiance). The modification of K91 (equation (4)) with the coefficients to calculate the average $\mathrm{K} 490$ within the layer receiving $>10 \%$ of surface irradiance, however, did not improve the performance of K91 (equation (4)) as compared to NOMAD measurements. It suggests that a lookup table giving the coefficients of equation (4) may be necessary to calculate the average $K_{d}$ within different optical depth. Although in this case the performance from our model did not show significant improvement from the other three models, the validation results among these four models, however, should be applied with caution. The field data in Figure 9 were in fact part of observations used to develop the S09 algorithm (equation (9)). Since most data points from this in situ data set were from relatively clear water condition (e.g., $90 \%$ of data was from waters with $[\mathrm{Chl}]<3 \mathrm{mg} \mathrm{m}^{-3}$ and $60 \%$ of data from waters with $[\mathrm{Chl}]<1 \mathrm{mg} \mathrm{m}^{-3}$ ), PZ06 (equation (15)) showed no significant improvement from G89 (equation (2)), 

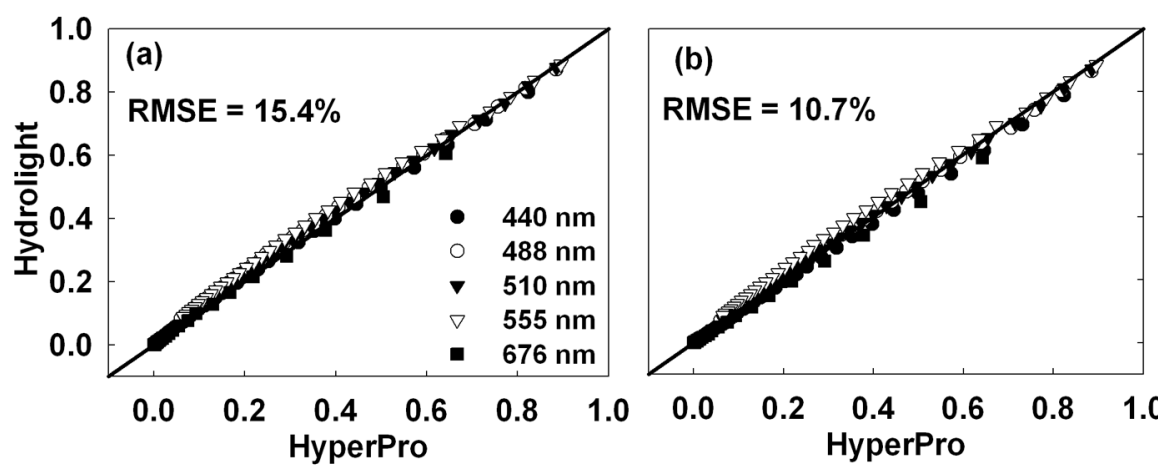

1.0

0.8

0.6

$0.4 \stackrel{\circ}{\text { N }}$

0.2

0.0
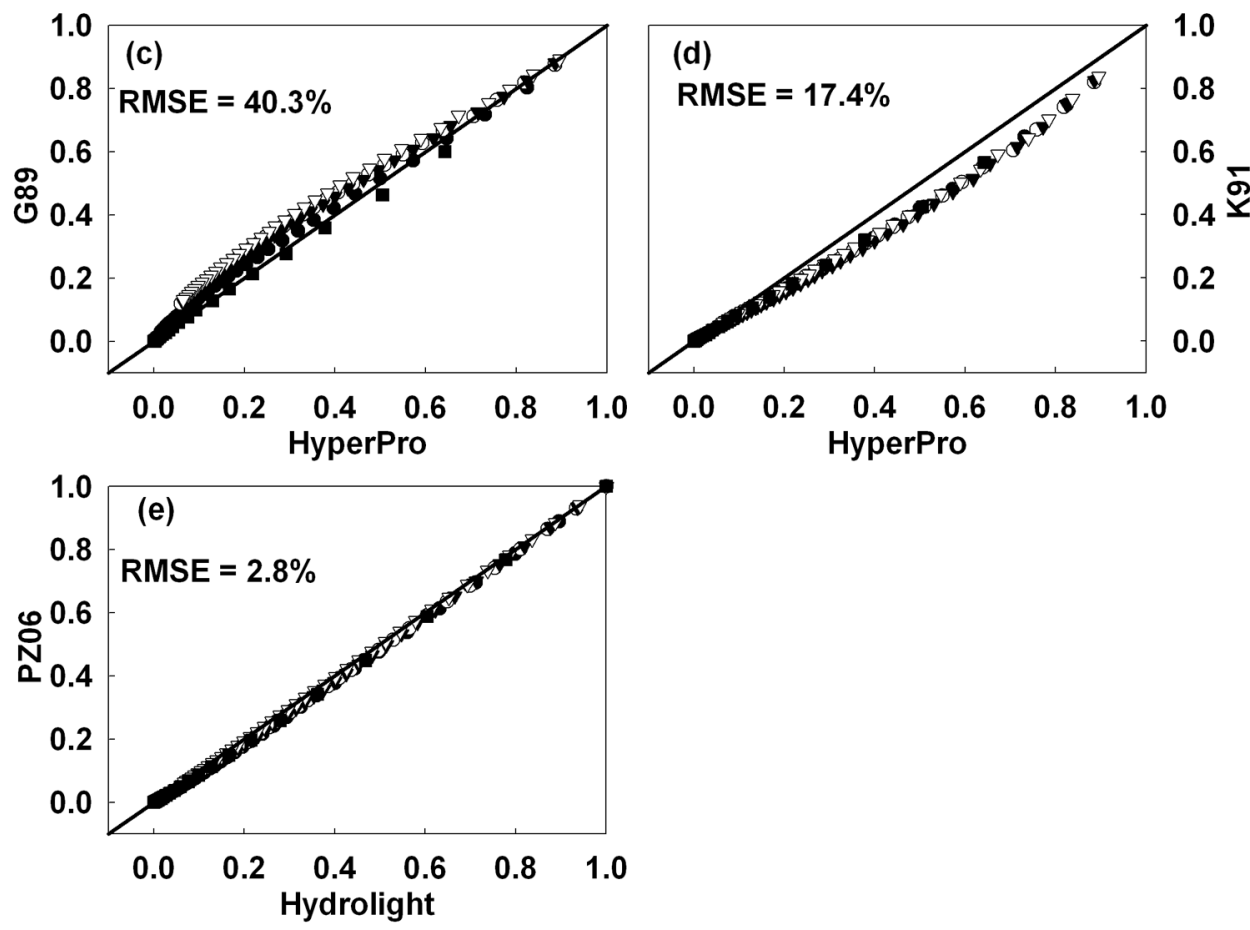

Figure 11. Comparisons of $E_{d}(z) / E_{d}\left(0^{-}\right)$for Station 6: plots (a)-(e) were same to those in Figure 10. For each symbol, comparisons for multiple depths from the surface to the depth with $1 \%$ of surface irradiance were shown.

K91 (equation (4)), or S09 (equation (9)) because these three models proved to work well in such conditions (Figure 7).

\subsection{Validation Against Field Observations of $E_{d}(z) /$ $E_{d}\left(0^{-}\right)$in the SMAB}

[21] In the coastal waters of the SMAB, both Hydrolight and PZ06 (equation (15)) reproduced the field observations better than the G89 (equation (2)), based on RMSE calculations at both Station 2 (Figures 10a and 10b) and Station 6 (Figures 11a and 11b). Without accounting for the scattering effect, G89 (equation (2)) tended to overestimate $E_{d}(z)$ (Figures 10c and 11c). Although K91 (equation (4)) produced similar RMSE results as Hydrolight and PZ06 (equation (15)), it seemed to underestimate $E_{d}(z)$ for the optically upper layer (Figures $10 \mathrm{~d}$ and $11 \mathrm{~d}$ ). Such underestimations were also consistent with the general performance of overestimating $\overline{K_{d}}(z)$ from NOMAD observations (Figure 9). After considering the relative difference between the HyperPro profiles (e.g., $5 \%$ and $6 \%$ of standard devia- tion at $676 \mathrm{~nm}$ for 3 profiles in Stations 2 and 4 profiles in Station 6), and the additional unqualified error caused by small-scale horizontal variability in water column optical properties (e.g., HyperPro was at least $20 \mathrm{~m}$ away from the ship to avoid the effects of ship shadow on radiance and AOPs, while $a c-9$ and HS- 6 were profiled just beside the ship because these IOP measurements were not affected by ship shadow), the RMSE of $10 \%$ to $15 \%$ may be reasonable. RMSEs between PZ06 (equation (15)) and Hydrolight simulations were $6.4 \%$ and $2.8 \%$ for Station 2 and Station 6 , respectively (Figure 10e and Figure 11e).

\subsection{Spatial Distribution of $K_{d}$ Derived From SeaWiFS Imagery}

[22] Figure 12 showed examples of SeaWiFS images of $K_{490}$ PZ06 for a winter date (3 November 2005, "2005307") and a summer date (12 May 2006, "2006132") in the SMAB. These images showed $K_{490}$ estimated from PZ06 (equation (15)) $\left(K_{490}\right.$ PZ06) decreased away from the coast, and particularly from the Chesapeake Bay mouth, out 


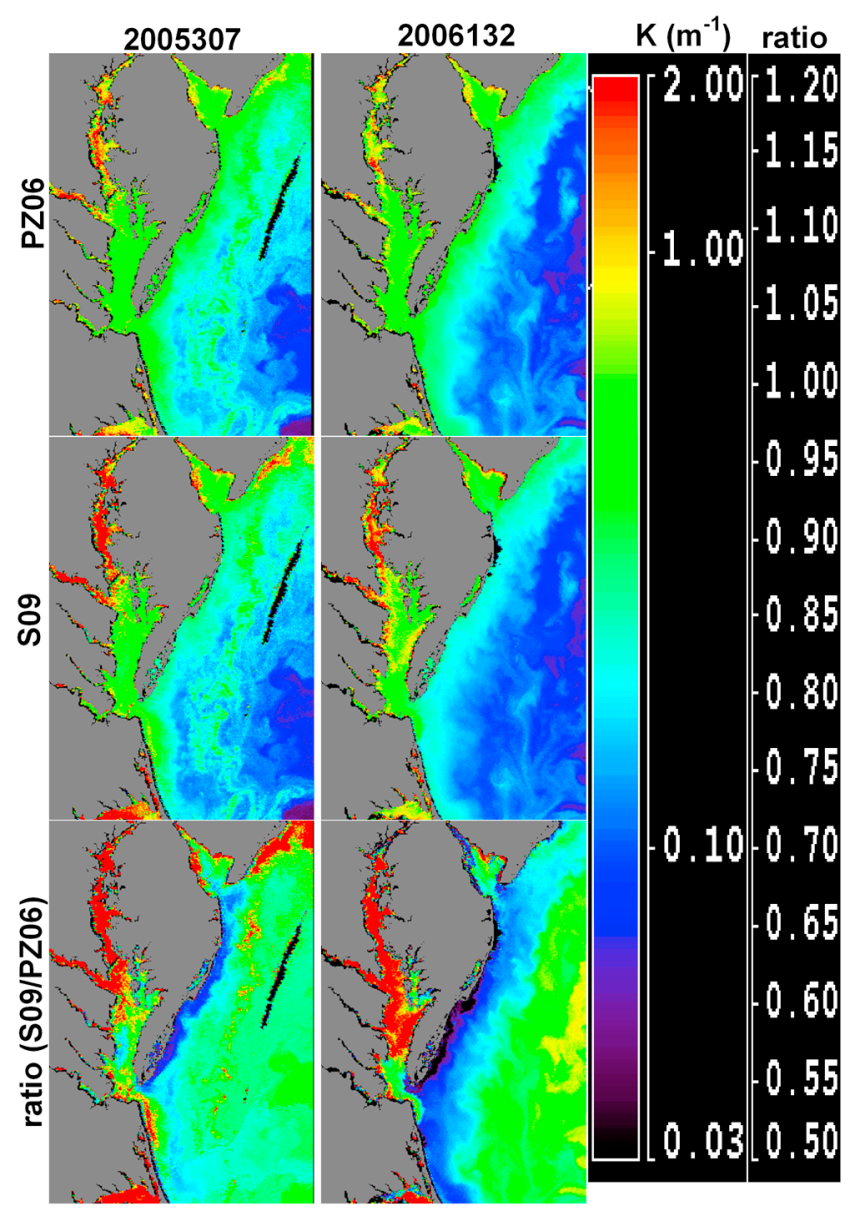

Figure 12. Sea-viewing Wide Field-of-view Sensor spatial distribution of the average diffuse attenuation coefficient from the surface to 1 optical depth at $490 \mathrm{~nm}$ estimated from PZ06 (equation (15)) and S09 (equation (9)) for a winter date (3 November 2005, "S2005307") and a summer date (12 May 2006, "S2006132”) in the southern Middle Atlantic Bight. The distribution of the ratio between these two models (S09/PZ06) is also shown.

toward the Atlantic Ocean. The primary frontal zone along Virginia/Carolina coast [Sletten et al., 1999] and the mixing of clear Gulf Stream waters with relatively turbid outflow waters were also evident. The derived values of $K_{490 \_P Z 06}$ for these images were consistent with typical in situ measurements. For instance, the field measurements conducted on 18 May 2005 showed surface $K_{d}(490)$ decreasing from $\sim 0.5 \mathrm{~m}^{-1}$ at near Cape Henry to $\sim 0.15 \mathrm{~m}^{-1}$ at the east of the Chesapeake Light Tower, similar to the values displayed for "2006132" (Figure 12). Although the distribution of $K_{490}$ estimated from S09 (equation (9)) (K490_S09) appeared qualitatively similar to our approach, the ratio of $K_{490}$ S09 to $K_{490}$ PZ06 indicated regions where these two approaches differed considerably. Without considering the Chesapeake Bay and Delaware plume regions, this ratio typically increases from $0.55-0.7$ on the inner shelf to $0.7-0.85$ on the middle shelf, and becomes more agreeable (0.85-1.1) toward offshore as waters become clearer, especially during summer (Figure 12). Such a trend was consistent with other works using the old versions of the operational algorithm, which showed significant underestimations of the diffuse attenuation coefficient in turbid waters (e.g., a factor of 2-3 in the Chesapeake Bay) [Mueller, 2000; Signorini et al., 2003; Wang et al., 2009]. The ratio of $K_{490}$ S09 to $K_{490}$ PZ06, however, is typically very close to 1 (e.g., 0.9-1.1) for the Chesapeake Bay plume region and the Delaware Bay (Figure 12). The different performance of the ratio between these two models can be due to the components contributing to the bio-optical properties. On the outer shelf and the open waters, CDOM is the dominant contributor (e.g., 50-70\% at $443 \mathrm{~nm}$ ) to the absorption [Pan et al., 2008]. Since CDOM is a nonscattering source [Mobley, 1994], the adding consideration of scattering impact from PZ06 (equation (15)) shows no significant improvement from the operational algorithm for the outer shelf and open waters (Figure 12). The NOMAD comparisons showed that the ratio of S09 (equation (9)) to the field measurements for the stations whose CDOM accounted for $>50 \%$ of absorption at $443 \mathrm{~nm}$ was close to 1 with the mean \pm SD of $0.993 \pm 0.292(\mathrm{~N}=$ 237). On the inner shelf, however, particles (phytoplankton plus nonpigmented particles) play increasing important role on the bio-optical properties [Pan et al., 2008]. The performance of S09 (equation (9)) then depends on, at least partly, the relative component concentrations of phytoplankton (typically larger size with lower backscattering ratio to scattering) and nonpigmented particles (typically smaller size with higher backscattering ratio to scattering). The NOMAD comparisons showed that the ratio of S09 (equation (9)) to the field measurements for the stations whose CDOM accounted for $<50 \%$ of absorption at $443 \mathrm{~nm}$ was close to 1 with the mean \pm SD of $1.048 \pm 0.429(\mathrm{~N}=$ 408) for the stations whose nonpigmented particles accounted for $<50 \%$ of particulate absorption at $443 \mathrm{~nm}$, and decreased to $0.700 \pm 0.477(\mathrm{~N}=60)$ when contribution from nonpigmented particles increased. The data used in Pan et al. [2008] showed that the contribution from nonpigmented particles to particulate absorption decreased as the increase of pigments, or lower ratio inside the Chesapeake Bay and the plume region. The S09 (equation (9)) products, thus, agreed better to PZ06 (equation (15)) for the Chesapeake plume region than for other inner shelf region (Figure 12). Since the phytoplankton growth in the lower Delaware Bay, in contrast to the lower Chesapeake Bay, is subject to light availability rather than nutrients [Harding et al., 1986; Marshall and Alden, 1993], the contribution from nonpigmented particles to particulate absorption is higher than that in the lower Chesapeake Bay [Pan et al., 2008]. The S09 (equation (9)) products then showed typical lower values than PZ06 (equation (15)) in the lower Delaware Bay (Figure 12). In summary, our approach may imply an improvement to estimate $K_{490}$ for turbid water as compared to S09 (equation (9)), especially for regions with higher sedimentary resuspension.

[23] Figure 13 showed the time series comparisons of $K_{d}(490)$ derived from S09 (equation (9)) and PZ06 (equation (15)) for three selected stations along the Chesapeake Bay estuary during 2005. Station (Stn) A (-75.88 W, $36.91^{\circ} \mathrm{N}$ ) represents a station on the inner shelf influenced significantly by the river discharge, while $\operatorname{Stn} \mathrm{B}\left(-75.64^{\circ} \mathrm{W}\right.$, $\left.36.92^{\circ} \mathrm{N}\right)$ and $\operatorname{Stn} \mathrm{C}\left(-74.50^{\circ} \mathrm{W}, 36.50^{\circ} \mathrm{N}\right)$ represent stations on the middle shelf and outer shelf. The derivations from S09 (equation (9)) were generally lower than those from PZ06 (equation (15)) and more agreeable to each other for 


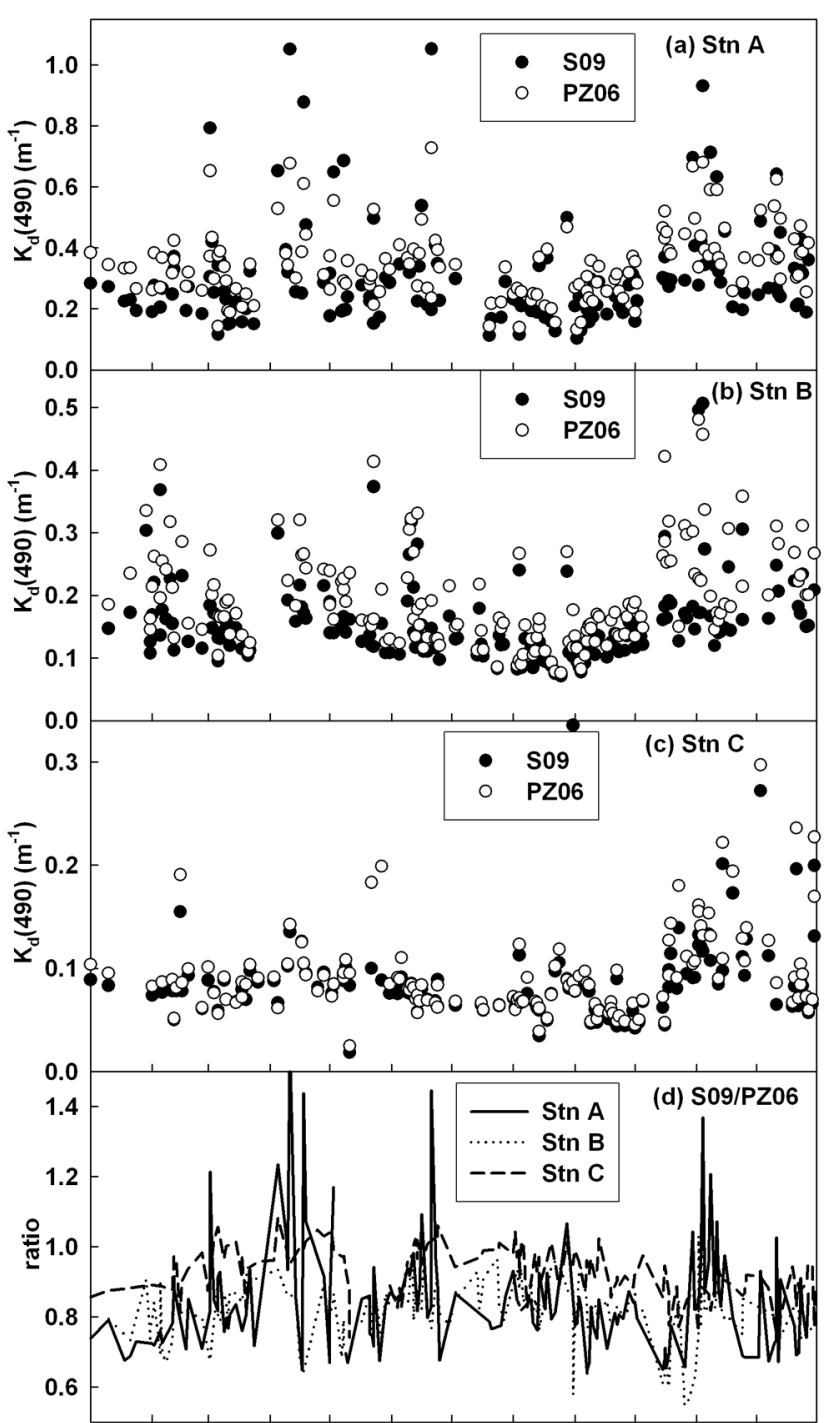

Jan Feb Mar Apr May Jun Jul Aug Sep Oct Nov Dec Date (2005)

Figure 13. Time series of the diffuse attenuation coefficient $\left[K_{d}(490)\right]$ estimated from S09 (equation (9)) and PZ06 (equation (15)) for three selected stations during 2005. (a) Station (Stn) A $\left(-75.88^{\circ} \mathrm{W}, 36.91^{\circ} \mathrm{N}\right)$, (b) Stn B $\left(-75.64^{\circ}\right.$ $\left.\mathrm{W}, 36.92^{\circ} \mathrm{N}\right)$, and (c) $\operatorname{Stn} \mathrm{C}\left(-74.50^{\circ} \mathrm{W}, 36.50^{\circ} \mathrm{N}\right)$ represent stations on the inner, middle, and outer shelf, respectively. (d) The ratio of S09/PZ06.

those regions with less impacts from river discharge, e.g., the ratio (S09/PZ06) increasing from the middle shelf $(81.3 \pm$ $8.8 \%)$ to the outer shelf $(92.8 \pm 7.1 \%)$ (Figure 13$)$. The ratio (S09/PZ06) was more variable on the inner shelf $(84.1 \pm$ $15.7 \%$ ) (Figure 13) as the increase of impact from the river discharge. Such results agreed with the analyses for the spatial distributions of the diffuse attenuation coefficients estimated by these two models (Figure 12).

\section{Discussion}

[24] Unlike the empirical algorithm derived from ratios of $R_{r s}$ optical bands [Mueller, 2000; Signorini et al., 2003],
PZ06 (equation (15)) is based on a radiative transfer analysis that provides a robust but quasi-mechanistic relationship between $K_{d}(z)$ and IOPs although the derivation of IOPs could be empirical (e.g., the application of our model to the SMAB region). Thus, it overcomes the uncertainty by the empirical algorithm (S09 or equation (9)), especially when the in situ data set does not cover whole range of water condition. In general, PZ06 (equation (15)) provides the same accuracy level for all water conditions, while S09 (equation (9)) has lower capability in very clear water and more turbid water conditions [Mueller, 2000; Signorini et al., 2003]. Although the simple formations of G89 (equation (2)) has been applied widely to bio-optics, its shortcoming in significantly underestimating $K_{d}(z)$ without considering the scattering effect is obvious (Figures 10 and 11), especially in particle-rich water conditions. Kirk [1991] model (K91, or equation (4)), in the other way, is subject to the difficulty to parameterize the appropriate coefficients related to scattering phase function. Since most of field data from the adapted NOMAD data set were collected from waters with medium particles (e.g., 90\% of stations whose [Chl $]<3 \mathrm{mg} \mathrm{m}^{-3}$ ) and medium solar positions (e.g., $83 \%$ of stations whose $\theta_{s}<60^{\circ}$ ), the validation performance from PZ06 (equation (15)) did not show significant improvement from G89 (equation (2)), K91 (equation (4)), or S09 (equation (9)). Limited field data from Case 2 waters (e.g., the southern Middle Atlantic Bight) and Hydrolight simulations, however, proved that significant improvement in estimating $K_{d}$ from our algorithms may be accomplished over the other models.

[25] The "exact" radiative transfer models (RTMs; e.g., Hydrolight) provide very useful tool in studying inwater bio-optical characteristics for individual stations, but they are not suitable to inversely derive AOPs or IOPs from satellite remote sensing observations. The application of RTMs or PZ06 (equation (15)) to derive $K_{d}$ from satellite remote sensing depends on satellite-derived IOPs. The running times of RTMs to calculate $K_{d}$ from IOPs, however, are typically very expensive, which limits their applications to process satellite images. PZ06 (equation (15)), in contrast, based on the statistical results of RTM simulations, provides an operational and quick method to obtain $K_{d}$ from satellitederived IOPs with reasonable and robust accuracy. Although more complicated than G89 (equation (2)), K91 (equation (4)), and S09 (equation (9)) performance, the improvement of computer capability will overcome the requirement of complicate calculations in accurately estimating the important bio-optical property, $K_{d}$. Expressed as a simple equation, PZ06 (equation (15)) is also suitable to apply to further bio-optical studies, e.g., in retrieving IOPs for optically shallow water conditions, which is difficultly solved by RTMs [Pan, 2007].

[26] PZ06 (equation (15)) assumes the water is optically deep. When the water column is optically shallow, the upwelling irradiance $\left(E_{u}\right)$ originating from bottom reflectance and its second-order contribution to $E_{d}(z)$ need to be assessed. Although such a contribution is relatively small in the SMAB (usually $<1 \%$ based on Hydrolight simulations), it is not negligible in some extreme conditions (e.g., very bright floor and very strong backscattering coefficient of the Bahamas Banks) in which $E_{u}$ generalized by bottom reflectance may be $>10 \%$ of $E_{d}$, especially near the seafloor. 
In the SMAB, in which the bottom reflectance $\left(R_{b}\right)$ is relatively low (e.g., in general $R_{b}<0.1$ [Pan, 2007]), the second-order contribution of the bottom reflectance on $E_{d}(z)$ can be ignored. Thus, PZ06 (equation (15)) can be applied to photosynthetic models for estimating water column primary productivity [Behrenfeld and Falkowski, 1997; Behrenfeld et al., 2005] and benthic optical environment from which seagrass primary productivity and distribution can be estimated for the SMAB [Dierssen et al., 2003; Zimmerman, 2003].

[27] Since PZ06 (equation (15)) requires the detailed IOPs to calculate $K_{d}$, the ability of the inverse model to retrieve absorption, scattering, and backscattering coefficients is critical. Unfortunately, the complicated condition in coastal waters often causes some errors in retrieving IOPs. For example, GSM01 model [Garver and Siegel, 1997; Maritorena et al., 2002] requires the remote sensing reflectance $\left(R_{r s}\right)$ for all bands to be equally accurate, but strong CDOM absorption and inadequate knowledge of aerosol absorption and scattering often cause significant underestimation of $R_{r s}$ in the blue bands (e.g., 412 and 443 $\mathrm{nm})$ [Bailey and Werdell, 2006; Siegel et al., 2000]. Therefore, the retrievals of IOPs in this study have to depend partly on empirical algorithms [Pan et al., 2008] before the validations of semianalytical retrievals can be achieved.

\section{Conclusion}

[28] By dividing the incident solar beam into direct and diffuse sky components and separating the analyses of their vertical characteristics along the depth with the water depth gradient, PZ06 (equation (15)) successfully reproduces both the "exact" results of Hydrolight simulations and field observations of the vertical distribution of downwelling plane irradiance $\left[E_{d}(z)\right]$. It offers improvement over Gordon [1989] simpler model (which works better for upper layer than for lower layer), Kirk [1991] model (which works better for lower layer than for upper layer), and an operationally empirical algorithm [Mueller, 2000; Signorini et al., 2003] (which works better for clearer waters or turbid waters whose bio-optical properties dominated by CDOM or phytoplankton than for more turbid waters with relatively higher fraction of particles from nonpigmented particles). However, the accuracy of this approach depends significantly on the inverse retrieval of IOPs from $R_{r s}$, which may require tuning for regionally specific parameters, especially in nearshore coastal waters.

[29] Acknowledgments. We thank David Ruble, Victoria Hill, Margaret Stoughton, and Jasmine Cousins for help with field observations and comments on this manuscript. We are grateful to the help from the captain and the crew of R/V Fay Slover. We also thank D. Siegel, G. Mitchell, and all of their coinvestigators for releasing their SeaBASS data contributions to the public. We thank the Editor (Des Barton), and Jeremy Werdel and an anonymous reviewer for their thorough, thoughtful jobs and constructive comments. Financial support was provided by NASA (award NNG04GN77G). Funding for Mitchell data collected during ACE-Asia and the Japan-East Sea cruises was provided by NASA SIMBIOS and the Office of Naval Research, respectively.

\section{References}

Bailey, S. W., and P. J. Werdell (2006), A multi-sensor approach for the on-orbit validation of ocean color satellite data products, Remote Sens. Environ., 102, 12-23, doi:10.1016/j.rse.2006.01.015.
Bannister, T. T. (1992), Model of the mean cosine of underwater radiance and estimation of underwater scalar irradiance, Limnol. Oceanogr., 37, 773-780, doi:10.4319/lo.1992.37.4.0773.

Behrenfeld, M. J., and P. G. Falkowski (1997), Photosynthetic rates derived from satellite-based chlorophyll concentration, Limnol. Oceanogr., 42, 1-20, doi:10.4319/lo.1997.42.1.0001

Behrenfeld, M. J., E. Boss, D. A. Siegel, and D. M. Shea (2005), Carbonbased ocean productivity and phytoplankton physiology from space, Global Biogeochem. Cycles, 19, GB1006, doi:10.1029/2004GB002299.

Berwald, J., D. Stramski, C. D. Mobley, and D. A. Kiefer (1995), Influences of absorption and scattering on vertical changes in the average cosine of the underwater light field, Limnol. Oceanogr., 40, 1347-1357, doi:10.4319/ lo.1995.40.8.1347.

Dierssen, H. M., R. C. Zimmerman, R. A. Leathers, T. V. Downes, and C. O. Davis (2003), Ocean color remote sensing of seagrass and bathymetry in the Bahamas Banks by high-resolution airborne imagery, Limnol. Oceanogr., 48, 444-455.

Garver, S. A., and D. A. Siegel (1997), Inherent optical property inversion of ocean color spectra and its biogeochemical interpretation: 1. Time series from the Sargasso Sea, J. Geophys. Res., 102(C8), 18,60718,625, doi:10.1029/96JC03243.

Gordon, H. R., O. B. Brown, R. H. Evans, J. W. Brown, R. C. Smith, K. S. Baker, and D. K. Clark (1988), A Semianalytic Radiance Model of Ocean Color, J. Geophys. Res., 93(D9), 10,909-10,924, doi:10.1029/ JD093iD09p10909.

Gordon, H. R. (1989), Can the Lamert-Beer law be applied to the diffuse attenuation coefficient of ocean water? Limnol. Oceanogr., 34, 13891409, doi:10.4319/lo.1989.34.8.1389.

Gordon, H. R., and A. Morel (1983), Remote assessment of ocean color for interpretation of satellite visible imagery: a review, Springer-Verlag, New York (Lecture Notes on Coastal and Estuarine Studies Series, No. 4)

Gregg, W. W., and K. L. Carder (1990), A simple spectral solar irradiance model for cloudless marine atmospheres, Limnol. Oceanogr., 35, 1657 1675, doi:10.4319/lo.1990.35.8.1657

Harding, L., B. Messon, and T. Fisher (1986), Phytoplankton production in two east coast estuaries: Photosynthesis-light functions and patterns of carbon assimilation in Chesapeake and Delaware Bays, Estuarine Coastal Shelf Sci., 23, 773-806, doi:10.1016/0272-7714(86)90074-0.

Harding, L. W., A. Magnuson, and M. E. Mallonee (2005), SeaWiFS retrievals of chlorophyll in Chesapeake Bay and the mid-Atlantic bight, Estuarine Coastal Shelf Sci., 62, 75-94, doi:10.1016/j.ecss.2004.08.011.

Harrison, A. W., and C. A. Coombes (1988), An opaque cloud cover model of sky short wavelength radiance, Sol. Energy, 41(4), 387-392, doi:10.1016/0038-092X(88)90035-7.

Kirk, J. T. O. (1991), Volume scattering function, average cosines, and the underwater light field, Limnol. Oceanogr., 36, 455-467, doi:10.4319/ lo.1991.36.3.0455.

Kirk, J. T. O. (1994), Light and Phytosynthesis in Aquatic Ecosystems, 2nd ed., Cambridge Univ. Press, New York, doi:10.1017/ CBO9780511623370

Lee, Z.-P., K.-P. Du, and R. Arnone (2005), A model for diffuse attenuation coefficient of downwelling irradiance, J. Geophys. Res., 110, C02016, doi:10.1029/2004JC002275.

Liu, C.-C., K. L. Carder, R. L. Miller, and J. E. Ivey (2002), Fast and accurate model of underwater scalar irradiance, Appl. Opt., 41, 4962-4974, doi:10.1364/AO.41.004962.

Mannino, A., M. E. Russ, and S. B. Hooker (2008), Algorithm development and validation for satellite-derived distributions of DOC and CDOM in the U.S. Middle Atlantic Bight, J. Geophys. Res., 113, C07051, doi:10.1029/2007JC004493.

Maritorena, S., D. A. Siegel, and A. R. Peterson (2002), Optimization of a semianalytical ocean color model for global-scale applications, Appl. Opt., 41, 2705-2714, doi:10.1364/AO.41.002705.

Marshall, H. G., and R. W. Alden (1993), A comparison of phytoplankton assemblages in the Chesapeake and Delaware estuaries (USA), with emphasis on diatoms, Hydrobiologia, 269-270, 251-261, doi:10.1007/ BF00028024.

McCormick, N. J. (1995), Mathematical models for the mean cosine of irradiance and the diffuse attenuation coefficient, Limnol. Oceanogr., 40, 1013-1018, doi:10.4319/1o.1995.40.5.1013.

Mobley, C. (1994), Light and Water: Radiative Transfer in Natural Waters, 592 pp., Elsevier, San Diego, Calif.

Mobley, C. D., L. K. Sundman, and E. Boss (2002), Phase function effects on oceanic light fields, Appl. Opt., 41, 1035-1050, doi:10.1364/ AO.41.001035.

Morel, A., and B. Gentili (1991), Diffuse reflectance of oceanic waters: Its dependence on Sun angle as influenced by the molecular scattering contribution, Appl. Opt., 30, 4427-4438, doi:10.1364/AO.30.004427. 
Morel, A., and B. Gentili (1993), Diffuse reflectance of oceanic waters: 2. Bi-directional aspects, Appl. Opt., 32, 6864-6879, doi:10.1364/ AO.32.006864.

Mueller, J. L. (2000), SeaWiFS algorithm for the diffuse attenuation coefficient, K(490), using water-leaving radiances at 490 and $555 \mathrm{~nm}$, in SeaWiFS Postlaunch Calibration and Validation Analyses, Part 3, edited by S. B. Hooker and E. R. Firestone, NASA Tech. Memo., NASA TM206892, vol. 11, 24-27.

Pan, X. (2007), The observation, modeling, and retrieval of bio-optical properties for coastal waters of the southern Chesapeake Bay, Ph.D. dissertation, Dep. of Ocean, Earth, and Atmos. Sci., Old Dominion Univ. Norfolk, Virginia.

Pan, X., A. Mannino, M. E. Russ, and S. B. Hooker (2008), Remote sensing of the absorption coefficients and chlorophyll $a$ concentration in the United States southern Middle Atlantic Bight from SeaWiFS and MODIS-Aqua, J. Geophys. Res., 113, C11022, doi:10.1029/ 2008JC004852.

Petzold, T. J. (1972), Volume scattering functions for selected ocean waters, Scripps Institution of Oceanography (SIO Reference 72-78), San Diego.

Pope, R. M., and E. S. Fry (1997), Absorption spectrum (380-700 nm) of pure water, II, Integrating cavity measurements, Appl. Opt., 36, 87108723, doi:10.1364/AO.36.008710.

Prieur, L., and S. Sathyendranath (1981), An optical classification of coastal and oceanic waters based on the specific spectral absorption curves of phytoplankton pigments, dissolved organic matter, and other particulate materials, Limnol. Oceanogr., 26, 671-689, doi:10.4319/ lo.1981.26.4.0671.

Siegel, D. A., M. Wang, S. Maritorena, and W. D. Robinson (2000), Atmospheric correction of satellite ocean-color imagery: The black pixel assumption, Appl. Opt., 39, 3582-3591, doi:10.1364/AO.39.003582.
Signorini, S. R., S. B. Hooker, and C. R. McClain (2003), Bio-optical and geochemical properties of the south Atlantic subtropical gyre, $N A S A$ Tech. Memo., NASA TM-212253.

Sletten, M. A., G. O. Marmorino, T. F. Donato, D. J. McLaughlin, and E. Twarog (1999), An airborne, real aperture radar study of the Chesapeake Bay outflow plume, J. Geophys. Res., 104(C1), 1211-1222, doi:10.1029/ 1998JC900034.

Smith, R. C., and K. Baker (1981), Optical properties of clearest natural waters, Appl. Opt., 20, 177-184, doi:10.1364/AO.20.000177.

Wang, M., S. Son, and L. W. Harding Jr. (2009), Retrieval of diffuse attenuation coefficient in the Chesapeake Bay and turbid ocean regions for satellite ocean color applications, J. Geophys. Res., 114, C10011, doi:10.1029/2009JC005286.

Werdell, P. J., and S. W. Bailey (2005), An improved bio-optical data set for ocean color algorithm development and satellite data product validation, Remote Sens. Environ., 98(1), 122-140, doi:10.1016/j. rse.2005.07.001.

Zaneveld, J. R. (1989), An asymptotic closure theory for irradiance in the sea and its inversion to obtain the inherent optical properties, Limnol. Oceanogr., 34, 1442-1452, doi:10.4319/lo.1989.34.8.1442.

Zimmerman, R. C. (2003), A bio-optical model of irradiance distribution of photosynthesis in seagrass canopies, Limnol. Oceanogr., 48, 568-585.

X. Pan, Research Center for Environmental Changes, Academia Sinica, 128 Academia Road, Section 2, Taipei 115, Taiwan. (xpanx001@gmail. com)

R. C. Zimmerman, Department of Ocean, Earth, and Atmospheric Sciences, Old Dominion University, 4600 Elkhorn Avenue, Norfolk, VA 23529, USA. 